\title{
Thermal and Narrowband Multispectral Remote Sensing for Vegetation Monitoring From an Unmanned Aerial Vehicle
}

\author{
Jose A. J. Berni, Student Member, IEEE, Pablo J. Zarco-Tejada, Lola Suárez, and Elias Fereres
}

\begin{abstract}
Two critical limitations for using current satellite sensors in real-time crop management are the lack of imagery with optimum spatial and spectral resolutions and an unfavorable revisit time for most crop stress-detection applications. Alternatives based on manned airborne platforms are lacking due to their high operational costs. A fundamental requirement for providing useful remote sensing products in agriculture is the capacity to combine high spatial resolution and quick turnaround times. Remote sensing sensors placed on unmanned aerial vehicles (UAVs) could fill this gap, providing low-cost approaches to meet the critical requirements of spatial, spectral, and temporal resolutions. This paper demonstrates the ability to generate quantitative remote sensing products by means of a helicopter-based UAV equipped with inexpensive thermal and narrowband multispectral imaging sensors. During summer of 2007, the platform was flown over agricultural fields, obtaining thermal imagery in the 7.5-13- $\mu \mathrm{m}$ region $(40-\mathrm{cm}$ resolution) and narrowband multispectral imagery in the $400-800-\mathrm{nm}$ spectral region $(20-\mathrm{cm}$ resolution). Surface reflectance and temperature imagery were obtained, after atmospheric corrections with MODTRAN. Biophysical parameters were estimated using vegetation indices, namely, normalized difference vegetation index, transformed chlorophyll absorption in reflectance index/optimized soil-adjusted vegetation index, and photochemical reflectance index (PRI), coupled with SAILH and FLIGHT models. As a result, the image products of leaf area index, chlorophyll content $\left(C_{\mathrm{ab}}\right)$, and water stress detection from PRI index and canopy temperature were produced and successfully validated. This paper demonstrates that results obtained with a low-cost UAV system for agricultural applications yielded comparable estimations, if not better, than those obtained by traditional manned airborne sensors.
\end{abstract}

Index Terms-Multispectral, narrowband, radiative transfer modeling, remote sensing, stress detection, thermal, unmanned aerial system (UAS), unmanned aerial vehicles (UAVs).

Manuscript received December 14, 2007; revised August 3, 2008 and September 13, 2008. This work was supported in part by the Spanish Ministry of Science and Education (MEC) under Projects AGL2005-04049, EXPLORAINGENIO AGL2006-26038-E/AGR, and CONSOLIDER CSD2006-67, and in part by Junta de Andalucía-Excelencia AGR-595.

J. A. J. Berni, P. J. Zarco-Tejada, and L. Suárez are with the Institute for Sustainable Agriculture, Spanish Council for Scientific Research, 14004 Córdoba, Spain (e-mail: pzarco@ias.csic.es).

E. Fereres is with the Institute for Sustainable Agriculture, Spanish Council for Scientific Research, 14004 Córdoba, Spain, and also with the Departamento de Agronomía, University of Córdoba, 14071 Córdoba, Spain.

Color versions of one or more of the figures in this paper are available online at http://ieeexplore.ieee.org.

Digital Object Identifier 10.1109/TGRS.2008.2010457

\section{INTRODUCTION}

$\mathbf{R}$ EMOTE sensing for agricultural and crop-management applications aims at providing spatially and spectrally derived surface parameters for crop classification and mapping [1]-[3], crop forecasting and yield predictions [4]-[7], crop status and condition [8]-[11], weed detection [12]-[14], disease detection and nutrient deficiency [15]-[17], and photosynthetic pigment content [18]-[20]. Critical issues such as the optimum spatial and spectral resolutions, the turnaround time, and repeat cycle are main factors limiting the usefulness of remote sensing products for precision crop management [21]; in addition, data acquisition costs must be weighed against anticipated benefits. Current satellite-based products have limited application in crop management due to the low spatial and spectral resolutions provided and the large revisit periods. Spatial resolution has been improved in some new satellite sensors such as Ikonos or Quickbird, however lacking the narrow spectral bands required for quantitave parameter retrievals on which most of the applications mentioned before are based. Moreover, thermal imaging is currently limited to medium-resolution sensors such as TERRA-ASTER [22], providing 90-m pixel size images which are impractical for site-specific agricultural applications.

Alternatives based on airborne sensors can deliver higher spatial and spectral resolutions and are more flexible in terms of revisit time. Airborne remote sensing has demonstrated capabilities for vegetation condition monitoring due to high spatial and spectral resolutions used, ranging between 0.5 - and 2-m pixel sizes with 2-20-nm bandwidths in the 400-2500-nm spectral range. The works conducted for crop management and stressdetection applications, such as the estimation of chlorophyll content with the Compact Airborne Spectrographic Imager [23]-[26], leaf water content from the Airborne Visible Infrared Imaging Spectrometer [27]-[31], carotenoid estimation [19], [32], dry matter content [33]-[35], and structural parameters like ground cover and leaf area index (LAI) minimizing background effects on traditional indices such as normalized difference vegetation index (NDVI) [36], are examples of the use of airborne sensors. In addition, high-spatial-resolution thermal imagery has demonstrated high potential for water stress detection in crops because of the increased temperature of stressed vegetation [37], [38], enabling the detection of water-stressed trees in orchards for site-specific field management [39]-[41]. However, the high operating costs, long turnaround times due to high volume of data processing acquired in large airborne campaigns, and the lack of private corporations providing 
cost-effective products have limited the use of airborne so far to research activities.

Back in 1977, Jackson et al. [37] envisioned a fleet of airborne thermal scanners collecting remote sensing imagery over irrigated fields to generate maps for irrigation scheduling based on an automated decision support system. However, after 30 years, this vision still seems futuristic due to the mentioned limitations mostly based on the costs required and the operational complexity involved. Another potential application of canopy temperature measurements is its capability for genotype screening in breeding programs for drought resistance [42], [43]. A new era of remote sensing is emerging with the arrival of unmanned aerial vehicles (UAVs) for civil applications. Scientific interest in this type of platforms is growing, and a number of experiences have already been reported. Large fixedwing UAVs, most of them NASA-funded, have been tested for agricultural applications, such is the case of the solar-powered Pathfinder Plus over coffee orchards in Hawaii [44], [45], the smaller RCATS/APV-3 tested over California vineyards [46], or the future European Pegasus UAV [47]. Miniaturization and cost reduction of inertial sensors, GPS devices, and embedded computers have enabled the use of a new generation of autopilots for inexpensive model aircrafts [48], [49]. At present time, commercial off-the-shelf (COTS) autopilots are readily available for an easy integration with small model aircrafts. Rotary-wing UAVs are also available, but complexity of the flight control system, smaller endurance, and the lack of autopilots supporting helicopter platforms have prevented a wide use of this platform. However, some successful applications have also been developed [50]-[52].

Along with the development of low-cost autopilot systems, also imaging sensors have suffered a critical size, weight, and price reduction, evolving from large sensors, rack-mounted dataloggers, and control computers to palm size imagers that can be easily installed into these microaircrafts [44], [48]. An example is the development of uncooled thermal instruments which avoid the use of heavy and expensive cooled sensors yet obtaining similar results at better spatial resolutions. The main problem concerning this type of microsensors is that they require spectral and geometric characterization to retrieve physical values such as ground reflectance or surface temperature. This is the reason why most of the applications mentioned before focused only on digital values or visual qualitative interpretation.

This paper describes the integration of COTS optical and thermal sensors placed on an unmanned aerial platform, focusing into radiometric quality of the acquired imagery. The main objective of this paper was to demonstrate that it is possible to combine successfully an unmanned rotary-wing platform and digital multispectral and thermal sensors, along with the appropriate calibrating methodologies, for agricultural applications. The assessment is conducted on narrowband vegetation indices in the 400-1000-nm and thermal spectral regions for quantitative parameter retrievals. Narrowband vegetation indices and thermal retrieval from crop canopies were then used to generate maps that could assist managers in water stress detection and many other site-specific applications in agriculture. In particular, this paper deals with the estimation of biophysical parameters such as LAI, chlorophyll content, a previsual indicator of stress based on the Photochemical Reflectance Index (PRI) [53], and water stress detection using thermal imagery. Calibration and atmospheric effects are also considered and assessed for the correct retrieval of parameters from the UAV system.

\section{Methods}

The UAV helicopter platform was developed to carry a payload with thermal and multispectral imaging sensors for remote sensing operation. A total of 288 flights were conducted in spring and summer of 2007 for both flight testing and imagery acquisitions over crop fields for parameter validation and stress detection using narrow spectral bands and thermal imagery. A description of the payload, sensor calibration, physical models used for parameter retrievals from multispectral imagery, and thermal corrections to account for atmospheric transmission are given hereinafter.

\section{A. UAV and Payload Description}

The UAV airframe used in this paper was based on a model helicopter (Benzin Acrobatic, Vario, Germany), modified to carry the camera system, autopilot, and sensors. Modifications consist mainly in a larger engine ( $29 \mathrm{cc}$ ), oversized landing skids, and a container for camera installation. The UAV was controlled by an autopilot system (model AP04H, UAV Navigation, Madrid, Spain) which provided autonomous navigation based on waypoints programmed during the mission planning. The air segment [Fig. 1(a)] consists on a dual CPU logic which controls an integrated Attitude Heading Reference System (AHRS) based on an L1 GPS board, three-axis accelerometers, yaw rate gyros, and a three-axis magnetometer. The CPUs continuously monitored internal sensors for battery status, internal temperature, and barometric pressure, including an external revolutions per minute (RPM) sensor. The guidance is based on standard servos controlled by pulsewidth modulation outputs from the autopilot. A radio link communicates with the ground segment sending telemetry of position, attitude, and status at $20-\mathrm{Hz}$ frequency. The ground segment [Fig. 1(b)] consists on a control box which contains a CPU that is in charge of processing the safety manual control and sends the telemetry to a laptop PC where the user application is running. This application monitors the status and position of the UAV and allows the user to upload and modify the flight plan. There is an additional GPS antenna on the ground control station used for pointing the telemetry antenna toward the UAV platform.

The flight plans are performed starting with the autonomous takeoff, continuing with an autonomous flight over a number of way points at a given altitude, and finally landing (Fig. 2). Flight altitude was selected depending on the study area to cover, camera field of view (FOV), and the desired spatial resolution for remote sensing imagery acquisition. The nominal speed in autonomous mode was fixed at $30 \mathrm{~km} / \mathrm{h}$.

1) Multispectral Camera: The multispectral sensor used in this paper was a six-band multispectral camera (MCA-6, Tetracam, Inc., CA, U.S.). The camera consists of six independent image sensors and optics with user configurable filters. The 

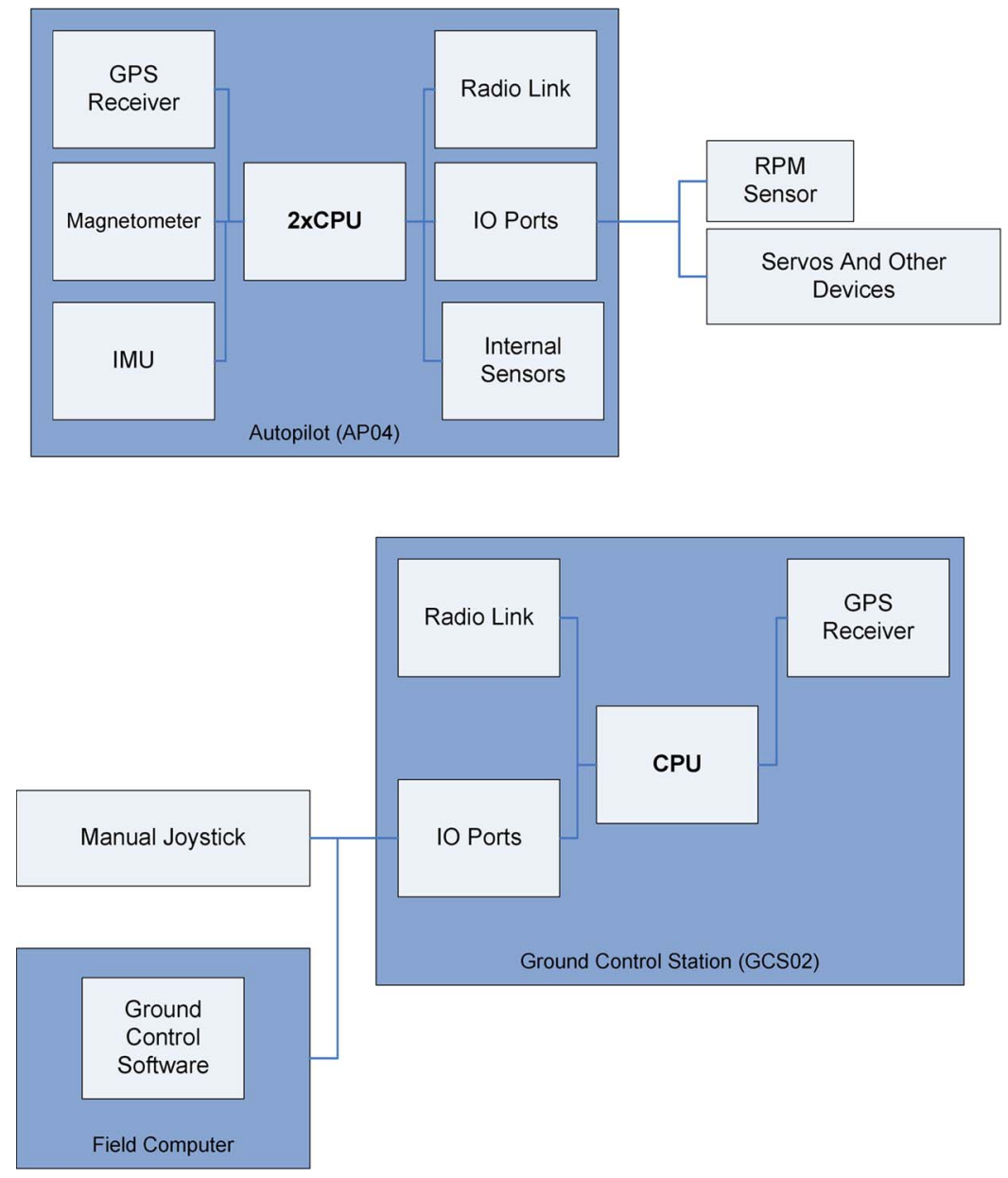

Fig. 1. Block diagram showing the components for the (a) autopilot and (b) ground control station.
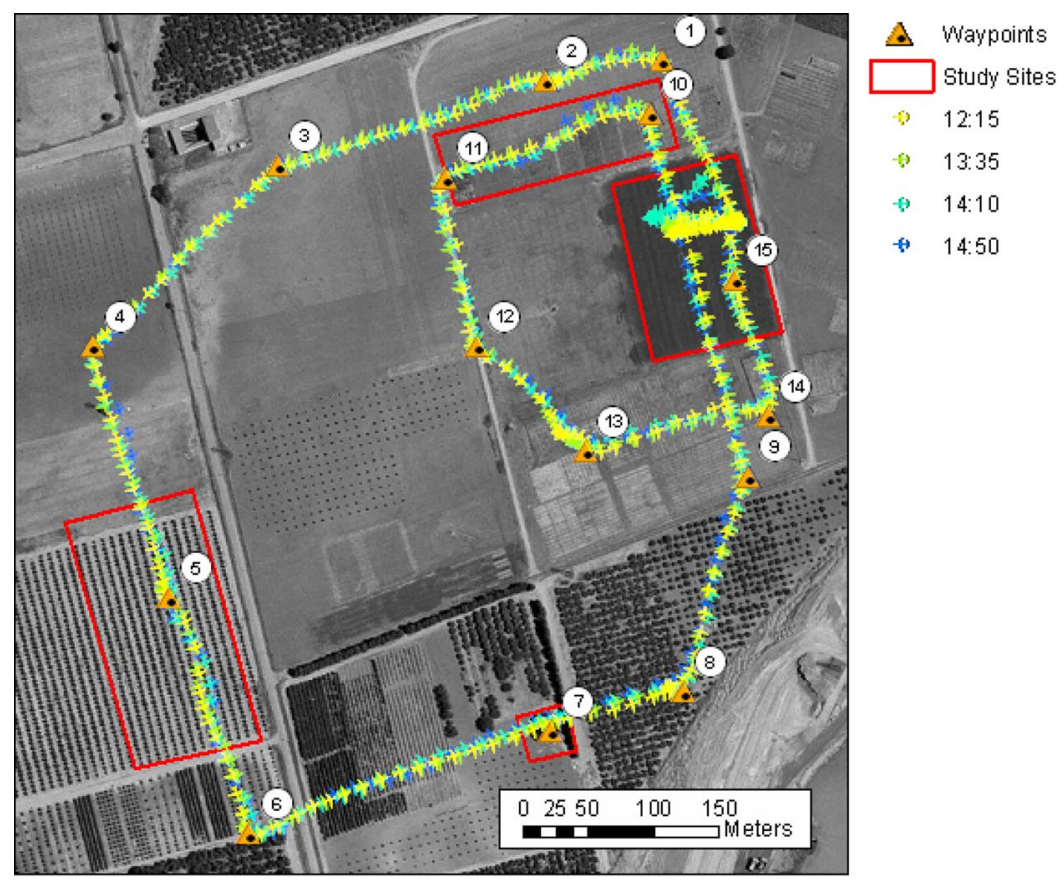

Fig. 2. Sample flight plan undertaken over four study sites, showing the path followed by the platform. Each numbered triangle symbols represent a waypoint programmed on the autopilot's flight plan. Four consecutive flights are overlapped, showing the precise paths followed by the UAV. 
This article has been accepted for inclusion in a future issue of this journal. Content is final as presented, with the exception of pagination.

TABLE I

Multispectral MCA-6 Image Sensor Specifications

\begin{tabular}{|l|l|}
\hline Array Elements & $1280 \times 1024$ \\
\hline Pixel Size & $5.2 \mu \mathrm{m} \times 5.2 \mu \mathrm{m}$ \\
\hline Image Area & $6.66 \mathrm{~mm} \times 5.32 \mathrm{~mm}$ \\
\hline Output & 10 -bit digital raw data \\
\hline Scan Mode & Progressive \\
\hline S/N Ratio & $54 \mathrm{~dB}$ \\
\hline Fixed Pattern Noise & $<0.03 \% V_{\text {PEAK-TO-PEAK }}$ \\
\hline Dark Current & $28 \mathrm{mV} / \mathrm{s}$ \\
\hline Dynamic Range & $60 \mathrm{~dB}$ \\
\hline Total weight $(6$ sensors $)$ & $2.7 \mathrm{~kg}$ \\
\hline
\end{tabular}

TABLE II

THERMAL FLIR IMAGE SENSOR SPECIFICATIONS

\begin{tabular}{|l|l|}
\hline Array Elements & $320 \times 240$ \\
\hline Pixel Size & $38 \mu \mathrm{m} \times 38 \mu \mathrm{m}$ \\
\hline Spectral response & $7.5-13 \mu \mathrm{m}$ \\
\hline Sensibility & $0.08 \mathrm{~K}$ at $303 \mathrm{~K}$ \\
\hline Dynamic Range & $233 \mathrm{~K}-393 \mathrm{~K}$ \\
\hline Total weight & $1.7 \mathrm{~kg}$ \\
\hline
\end{tabular}

image resolution is $1280 \times 1024$ pixels with 10-bit radiometric resolution and optics focal length of $8.5 \mathrm{~mm}$, yielding an angular FOV of $42.8^{\circ} \times 34.7^{\circ}$. Table I shows a summary of the multispectral camera sensor specifications. Different bandsets were used depending on the objectives sought for the remote sensing study, including 25-mm-diameter bandpass filters of 10-nm full-width at half-maximum (FWHM) (Andover Corporation, $\mathrm{NH}$, U.S.), with center wavelengths at $490,550,670$, 700,750 , and $800 \mathrm{~nm}$. The raw images were compressed on a proprietary format and stored on individual compact flash cards installed in the camera. Image triggering was activated from the ground control station when the helicopter reached the desired study site.

2) Thermal Camera: The thermal imager used in this paper was the Thermovision A40M (FLIR, U.S.) equipped with a $40^{\circ}$ FOV lens and connected via IEEE-1394 protocol. The image sensor is a focal plane array based on uncooled microbolometers with a resolution of $320 \times 240$ pixels and spectral response in the range of 7.5-13 $\mu \mathrm{m}$ (Table II). The camera delivers digital raw images at 16 bits of at-sensor calibrated radiance with a dynamic range of $233 \mathrm{~K}-393 \mathrm{~K}$. The sensor implements an internal calibration for nonuniformity correction and internal temperature calibration. The camera was controlled by a PC104 embedded computer (Cool Little Runner 2, LiPPERT, Germany), storing one raw image on a compact flash card every $2 \mathrm{~s}$ over the entire flight. A laboratory calibration was conducted using a calibration blackbody source (RAYBB400, Raytek, CA, U.S.). During the calibration, a need for stabilization after switch on was noticed. Temperature changes over the course of $30 \mathrm{~min}$ show the convergence to the black body temperature (Fig. 3). Absolute temperature shifts observed were caused by the internal camera calibration which is automatically activated when the internal temperature changes above a configured value. A 1-h camera stabilization procedure was conducted before each remote sensing campaign.

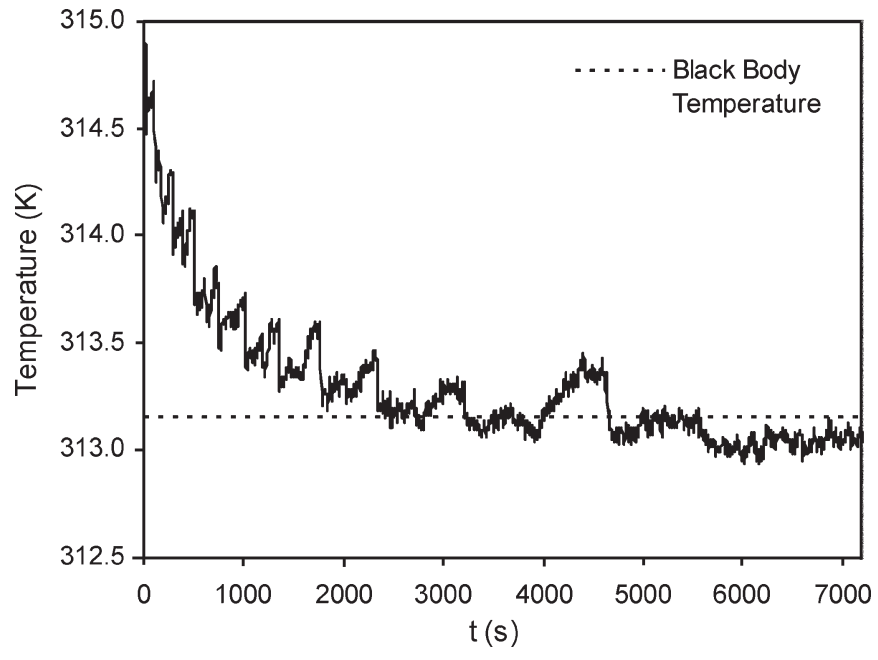

Fig. 3. Changes of the radiometric temperature measured by the camera after power-on over the course of $2 \mathrm{~h}$.

TABLE III

FLIR AND MCA CAMERAS INTRINSIC PARAMETERS

\begin{tabular}{|l|r|l|r|l|}
\hline fc & 16.999 & $\mathrm{~mm}$ & 8.474 & $\mathrm{~mm}$ \\
\hline $\mathrm{xc}$ & 0.0254 & $\mathrm{~mm}$ & 0.1307 & $\mathrm{~mm}$ \\
\hline $\mathrm{yc}$ & -0.0998 & $\mathrm{~mm}$ & 0.1501 & $\mathrm{~mm}$ \\
\hline $\mathrm{k} 1$ & $-1.48861 \mathrm{E}-03$ & & $5.21444 \mathrm{E}-04$ & \\
\hline $\mathrm{k} 2$ & $-2.45442 \mathrm{E}-02$ & & $-3.81969 \mathrm{E}-03$ & \\
\hline $\mathrm{k} 3$ & $-3.53002 \mathrm{E}-03$ & & $3.30444 \mathrm{E}-05$ & \\
\hline
\end{tabular}

3) Camera Geometric Calibration: Several methodologies are available to conduct an accurate geometric calibration over nonmetric commercial cameras [54], [55]. The objective of this calibration is to recover the intrinsic camera parameters (focal distance, principal point coordinates, and lens radial distortion). In this case, Bouguet's calibration toolbox [56] was used, consisting of placing a calibration checkerboard pattern on a fixed location and acquiring several images from different locations and orientations. The grid corner coordinates were extracted semiautomatically from the images, and the intrinsic parameters and exterior orientation (EO) were calculated. In the case of the thermal camera, a calibration pattern was built using resistive wires to obtain a bright pattern when electricity circulated through the wires, thus increasing their temperature. Bouguet's model uses a different lens distortion model than the one implemented by the software employed for the aerotriangulation which is based on the study of Wolf [57]. In the former, radial and tangential distortion can be estimated. In this case, tangential distortion was neglected and only the radial component was taken into account. The equation for Bouguet's model is shown in (1), whereas Wolf's model is described in (2). A least squares adjustment was conducted to fit (2) to (1)

$$
\begin{aligned}
& d r=k_{1} r^{2}+k_{2} r^{4}+k_{5} r^{6} \\
& d r=k_{0} r+k_{1} r^{3}+k_{2} r^{5} .
\end{aligned}
$$

Table III shows the intrinsic parameters estimated for the thermal and multispectral cameras used in this paper. For the multispectral camera, in a second stage, one of the cameras was used as reference and the relative position of the rest of 
(a)
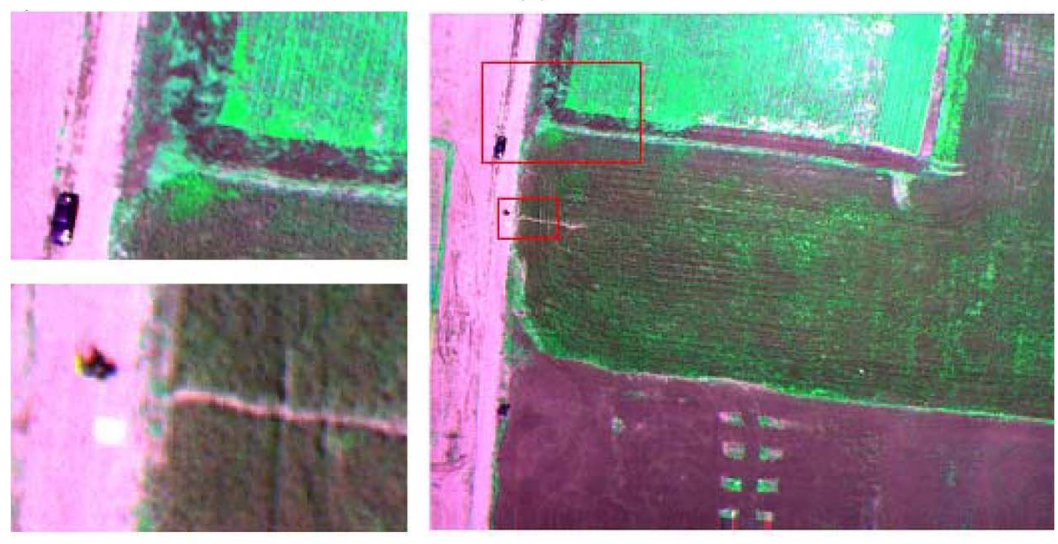

(b)

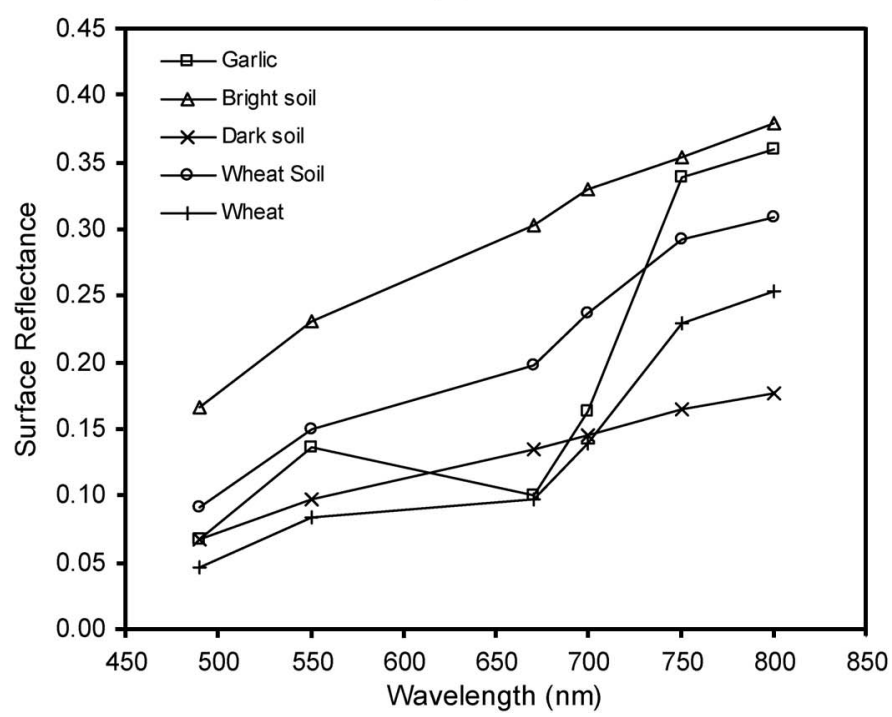

Fig. 4. (a) Multispectral imagery collected by the MCA-6 camera at 0.15-m spatial resolution and six spectral bands with 10-nm FWHM. (b) Spectra extracted from different image targets in the 400-800-nm spectral region.

the cameras was estimated by solving the system as different stereo rigs for each reference-camera pair.

\section{B. Multispectral Sensor Calibration and Vegetation Indices Used for Parameter Estimation}

Multispectral image calibration was conducted using the empirical line method [58] by placing two $2-\times 2$-m leveled dark and white targets in a central location within the flight path of the UAV platform. Field spectral measurements were taken on the calibration targets with an ASD field spectrometer (FieldSpec Handheld Pro, ASD Inc., CO, U.S.) in the 350-1050-nm spectral range at the time of image acquisition. The ASD field spectrometer was first calibrated using a Spectralon (SRT-99-180, LabSphere, NH, U.S.) white panel, therefore enabling the calculation of white and dark panel reflectance spectra to be used later for the empirical line calibration method.

The empirical line calibration method derived the coefficients needed to fit uncalibrated airborne MCA- 6 multispectral

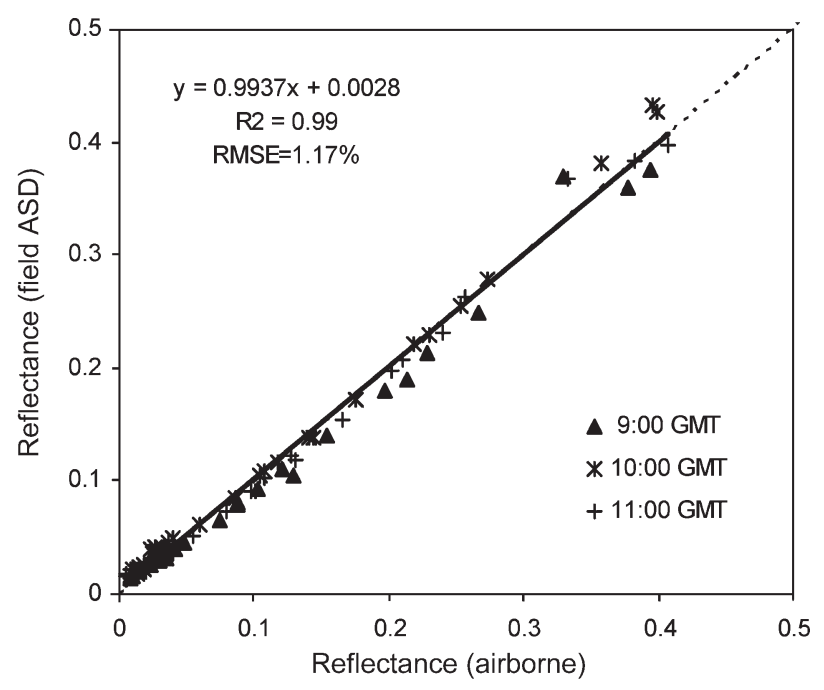

Fig. 5. Validation of the surface reflectance acquired by the MCA- 6 multispectral camera as compared with the ASD field spectrometer. The plot shows 90 points from 3 flights over 5 targets ( 3 corn crop sites, 1 soil target, and 1 cotton site) for 6 spectral bands. 
This article has been accepted for inclusion in a future issue of this journal. Content is final as presented, with the exception of pagination.

TABLE IV

Nominal Values and Parameters Used for Leaf and Canopy Modeling With PROSPECT and Flight for the Peach Study Site PROSPECT INPUTS

\begin{tabular}{|l|l|r|}
\hline Leaf Internal Structure Parameter & $\mathrm{N}$ & 1.8 \\
\hline Leaf Chlorophyll a+b content $\left(\mu \mathrm{g} / \mathrm{cm}^{2}\right)$ & $\mathrm{C}_{\mathrm{ab}}$ & $15,30,45,60,75,90$ \\
\hline Leaf equivalent water thickness $(\mathrm{cm})$ & $\mathrm{C}_{\mathrm{w}}$ & 0.0121 \\
\hline Leaf dry matter content $\left(\mathrm{g} / \mathrm{cm}^{2}\right)$ & $\mathrm{C}_{\mathrm{m}}$ & 0.003 \\
\hline Brown pigments relative parameter & $\mathrm{C}_{\mathrm{s}}$ & 0.001 \\
\hline
\end{tabular}

\section{FLIGHT INPUTS}

\begin{tabular}{|l|r|}
\hline Total leaf area index & $0.06035,0.1207,0.2413,0.3621,0.6035,0.8449$ \\
\hline Leaf angle distribution & $0.015,0.045,0.074,0.1,0.123,0.143,0.158,0.168,0.174$ \\
\hline Aerial optical thickness & 0.1 \\
\hline Soil roughness & 0.1 \\
\hline Leaf size (Equivalent radius, $\mathrm{m})$ & 0.02 \\
\hline Crown leaf area index (CLAl) & $0.5,1,2,3,5,7$ \\
\hline
\end{tabular}
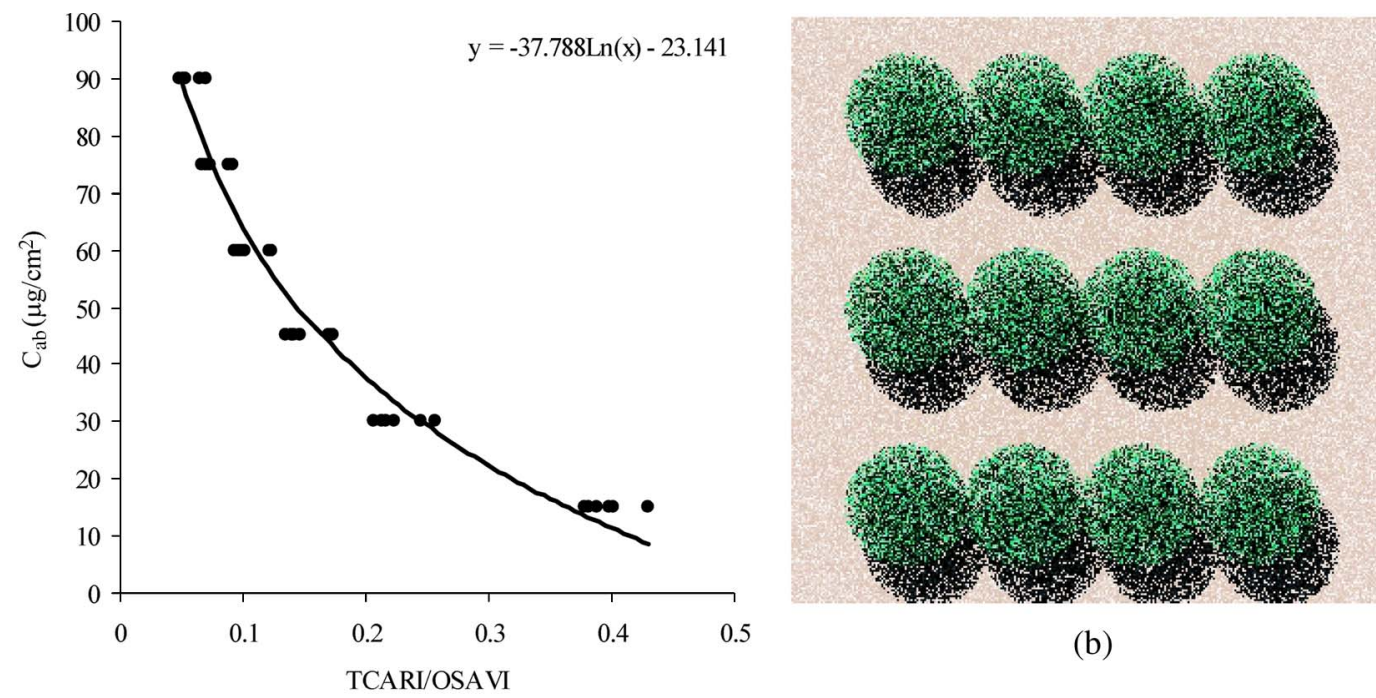

(b)

(a)

Fig. 6. (a) Algorithm to estimate chlorophyll $\mathrm{a}+\mathrm{b}$ from TCARI/OSAVI index developed with the FLIGHT radiative transfer model. Input parameters for simulating the peach orchard canopy reflectance ranged between 0.5 and 7 (LAI) and 15 and $90 \mu \mathrm{g} / \mathrm{cm}^{2}\left(C_{\mathrm{ab}}\right)$. (b) Sample 3-D scene simulated with FLIGHT model for developing the scaling-up algorithm to estimate chlorophyll concentration $\left(c L A I=2, C_{\mathrm{ab}}=45 \mu \mathrm{g} / \mathrm{cm}^{2}\right)$.

imagery to field-measured reflectance spectra. Fig. 4 shows sample imagery and reflectance spectra for different field targets acquired with the MCA-6 multispectral camera onboard the UAV platform over one of the study sites, which included a field planted with garlic, bright soil, dark soil, bare soil between wheat rows, and a wheat field. Spectra from the different targets clearly show the photosynthetic pigment absorption in the visible spectral region $(400-700 \mathrm{~nm})$ in green vegetation, with an increased reflectance due to canopy scattering in the near-infrared region beyond $700 \mathrm{~nm}$. A field validation assessment was conducted to evaluate the calibration method used to calculate surface reflectance by measuring reflectance spectra with the ASD field spectrometer over different targets found on imagery acquired at different times of day. Fig. 5 shows the validation of the calibration method using cotton and corn fields. UAV airborne flights were conducted three times over the course of one day in June 2007, acquiring field ASD spectra over cotton, corn with different canopy densities, and bare soil. The UAV MCA-6 spectral imagery and field spectra were compared and generally agreed, yielding an RMSE $=$ $1.17 \%(n=90)$ after empirical line methods were applied at each flight time.

Three vegetation indices were calculated from the airborne spectra using the six 10-nm FWHM bands of the multispectral camera. The NDVI [59] was calculated to assess the estimation of canopy LAI. The transformed chlorophyll absorption in reflectance index (TCARI) [60] based on the modified chlorophyll absorption in reflectance (MCARI) [61], normalized by the optimized soil-adjusted vegetation index (OSAVI) [62] to obtain TCARI/OSAVI, is demonstrated to successfully minimize soil background and LAI variation in crops, providing predictive relationships for chlorophyll concentration estimation with narrowband imagery in closed crops [60] and in open tree canopy orchards [25]. Finally, the PRI, originally developed for xanthophyll cycle pigment change detection [53], a potential indicator for carotenoid/chlorophyll ratio monitoring [32], [63], [64], was calculated to assess its potential capability for water stress detection from the UAV platform. 


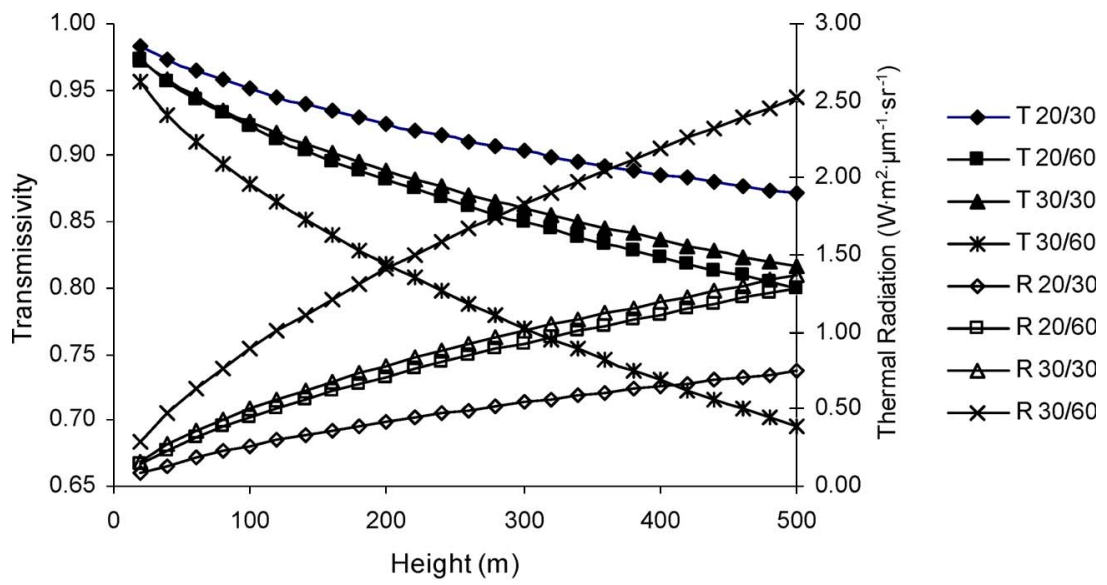

(a)

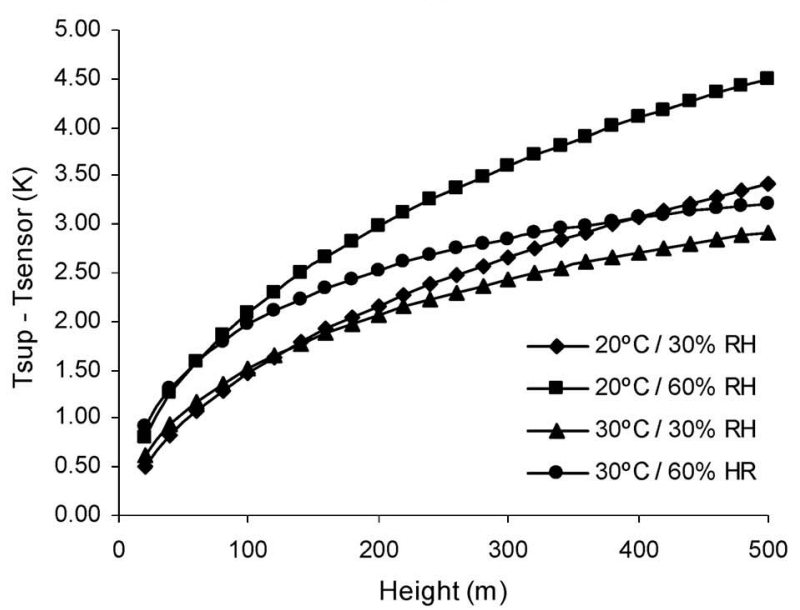

(b)

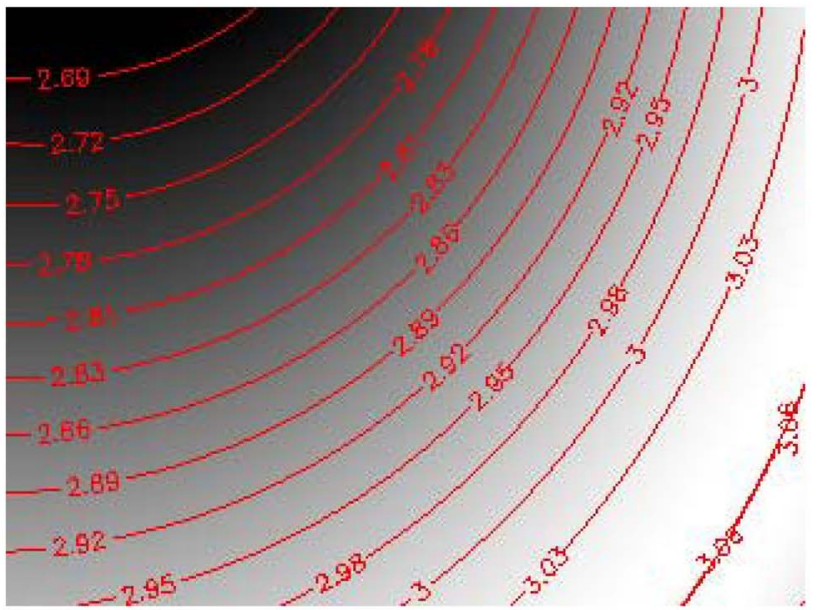

(c)

Fig. 7. (a) Simulated atmospheric transmittance and thermal radiation as a function of platform altitude. (b) Effects of flight altitude and atmospheric conditions $T_{a}\left({ }^{\circ} \mathrm{C}\right) / \% \mathrm{RH}$ on the surface temperature estimation for a back body at $300 \mathrm{~K}$. (c) Distribution of the atmospheric correction effects as a function of the off-nadir view for a uniform black body at $300 \mathrm{~K}$, atmospheric conditions $20^{\circ} \mathrm{C} / 60 \% \mathrm{RH}$, flight altitude of $150 \mathrm{~m}$, pitch $=10^{\circ}$, and roll $=6^{\circ}$.

The PRI index was calculated with the MCA-6 camera using additional 10-nm FWHM filters centered at 530- and 570-nm wavelengths. The three indices are described in the following equations:

$$
\begin{aligned}
& \text { TCARI/OSAVI } \\
& =\frac{3 \cdot\left[\left(R_{700}-R_{670}\right)-0.2 \cdot\left(R_{700}-R_{550}\right) \cdot\left(R_{700} / R_{670}\right)\right]}{(1+0.16) \cdot\left(R_{800}-R_{670}\right) /\left(R_{800}+R_{670}+0.16\right)}
\end{aligned}
$$

(3) $\quad P R I=\frac{R_{570}-R_{531}}{R_{570}+R_{531}}$.

$N D V I=\frac{R_{800}-R_{670}}{R_{800}+R_{670}}$ 
Field measurements of crown LAI (cLAI) were conducted with a plant canopy analyzer (LAI-2000; Li-Cor, NE, U.S.) on an olive orchard using the method reported in [65]. A total of six trees were measured and identified on the high-spatialresolution imagery acquired with the UAV platform. Field measurements of canopy LAI were also conducted on a variety trial corn field, and seven plots planted with different varieties were assessed. The mean spectral reflectance was calculated for each tree crown and variety plot, and indices were calculated. Relationships between field-measured crown and canopy LAI and the NDVI index were also developed.

Leaf-level radiative transfer model PROSPECT [66] was linked with the canopy-level Forest LIGHT Interaction Model (FLIGHT) [67] to obtain predicting algorithms for chlorophyll concentration $\left(C_{\mathrm{ab}}\right)$ from the airborne TCARI/OSAVI index. The modeling method consisted on ranging input chlorophyll $\mathrm{a}+\mathrm{b}$ from 15 to $90 \mu \mathrm{g} / \mathrm{cm}^{2}$ and cLAI from 0.5 to 7 . The rest of the input parameters were fixed for typical and field-measured structural parameters presented in Table IV. A total of 36 different input combinations were simulated, and TCARI/OSAVI was calculated from the modeled spectra [Fig. 6(a) and (b)]. Ground truth chlorophyll content was estimated for a total of 41 olive tree and peach crowns using the SPAD meter (SPAD502DL, Minolta, Japan). A total of 50 leaves were sampled from each crown, and mean SPAD measurements were used to estimate the total chlorophyll content through SPAD- $C_{\mathrm{ab}}$ relationships developed for each crop using destructive sampling methods based on spectrophotometer readings in the laboratory.

To assess the capability of PRI for stress detection from the UAV platform, the PRI was calculated from the MCA- 6 camera. A variety trial corn field was flown at different times during the course of the day, and variety plots that differed in water status were identified on the imagery. Assessment of PRI for stress detection was conducted by studying the relationships between PRI and plot temperature obtained from the UAV thermal and multispectral cameras. To remove the effects of canopy or soil temperature variations on the vegetation index, comparisons were made among corn plots with the same NDVI range.

\section{Methods for Surface Temperature Estimation}

Different methods have been proposed recently to retrieve surface temperature from thermal sensors. A review of methods can be found in [68]-[70]. The thermal sensor used in this paper provided a single band in the range of 7.5-13 $\mu \mathrm{m}$; therefore, only techniques developed for single-channel atmospheric correction were used. Methods based on the radiative transfer equation use (6) to estimate surface temperature. Needed parameters are atmospheric transmittance $\left(\tau_{\lambda}\right)$, emissivity $\left(\varepsilon_{\lambda}\right)$, downwelling $\left(L_{\mathrm{atm}, \lambda}^{\downarrow}\right)$, and upwelling thermal radiation $\left(L_{\mathrm{atm}, \lambda}^{\uparrow}\right)$, which are driven mainly by water vapor content, air temperature, and distance to object

$$
L_{\mathrm{sensor}, \lambda}=\left\lfloor\varepsilon_{\lambda} B_{\lambda}\left(T_{S}\right)+\left(1-\varepsilon_{\lambda}\right) L_{\mathrm{atm}, \lambda}^{\downarrow}\right\rfloor \cdot \tau_{\lambda}+L_{\mathrm{atm}, \lambda}^{\uparrow} .
$$

The MODTRAN radiative transfer code [71] was used to model $\tau_{\lambda}$ and $L_{\mathrm{atm}, \lambda}^{\uparrow}$, while $L_{\mathrm{atm}, \lambda}^{\downarrow}$ was measured in the field

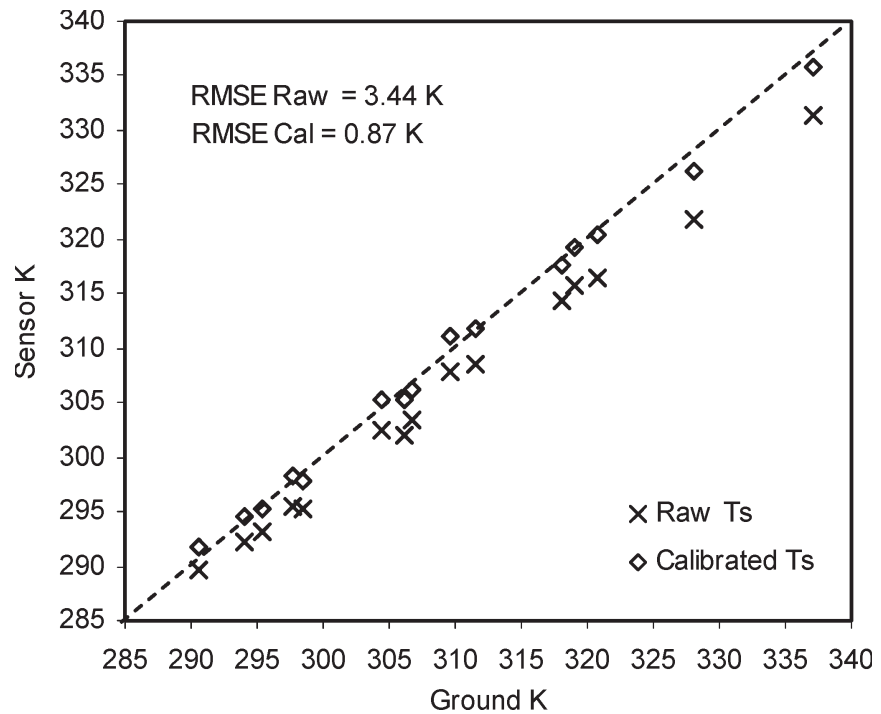

Fig. 8. Comparison between ground truth surface temperature (IRT measured) and that obtained from the thermal camera at 150-m flight altitude before $(x)$ and after (o) applying the atmospheric correction.

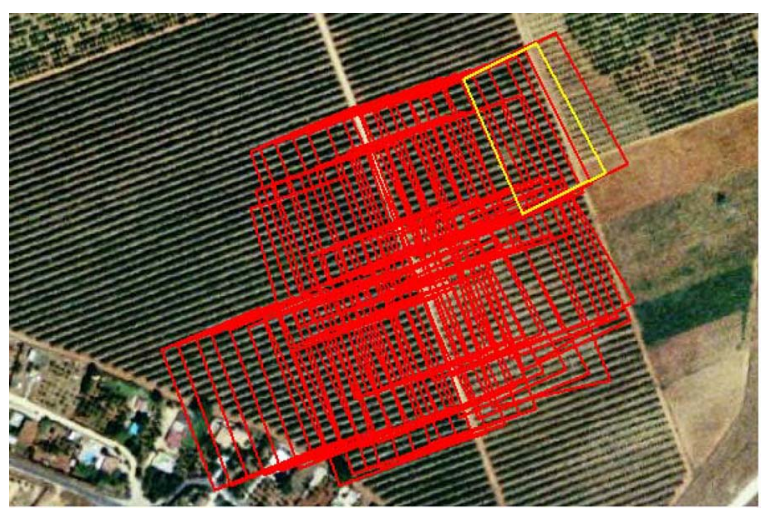

Fig. 9. Footprints for the images acquired during a flight plan conducted over an orange orchard. Red rectangles correspond to single image frames. The yellow rectangle represents the overlapping of two consecutive images (stereo-pair).

with a thermal sensor (LaserSight, Optris, Germany) pointing toward the zenith upward with an FOV of $15^{\circ}$ and a spectral response of $8-14 \mu \mathrm{m}$. Since only vegetation temperature was retrieved as part of this paper, a surface emissivity of 0.98 was considered as an accepted value for natural vegetation [72]. Local atmospheric conditions such as air temperature, relative humidity, and barometric pressure were measured at the time of flight with a portable weather station (Model WXT510, Vaisala, Finland) and used as input into MODTRAN model. A single-layer atmosphere with uniform conditions was considered for the simulations since the variation for the typical UAV flight altitude (150-200 m) could be neglected. Both path transmittance and thermal radiance were simulated at different sensor altitudes and integrated for the spectral response range of the thermal camera. Two fourth-grade polynomial relationships were fitted for transmittance and thermal radiation as a function of path length. The results for different atmospheric conditions are shown in Fig. 7(a), demonstrating that flight altitude can influence surface temperatures, if not corrected for atmospheric 

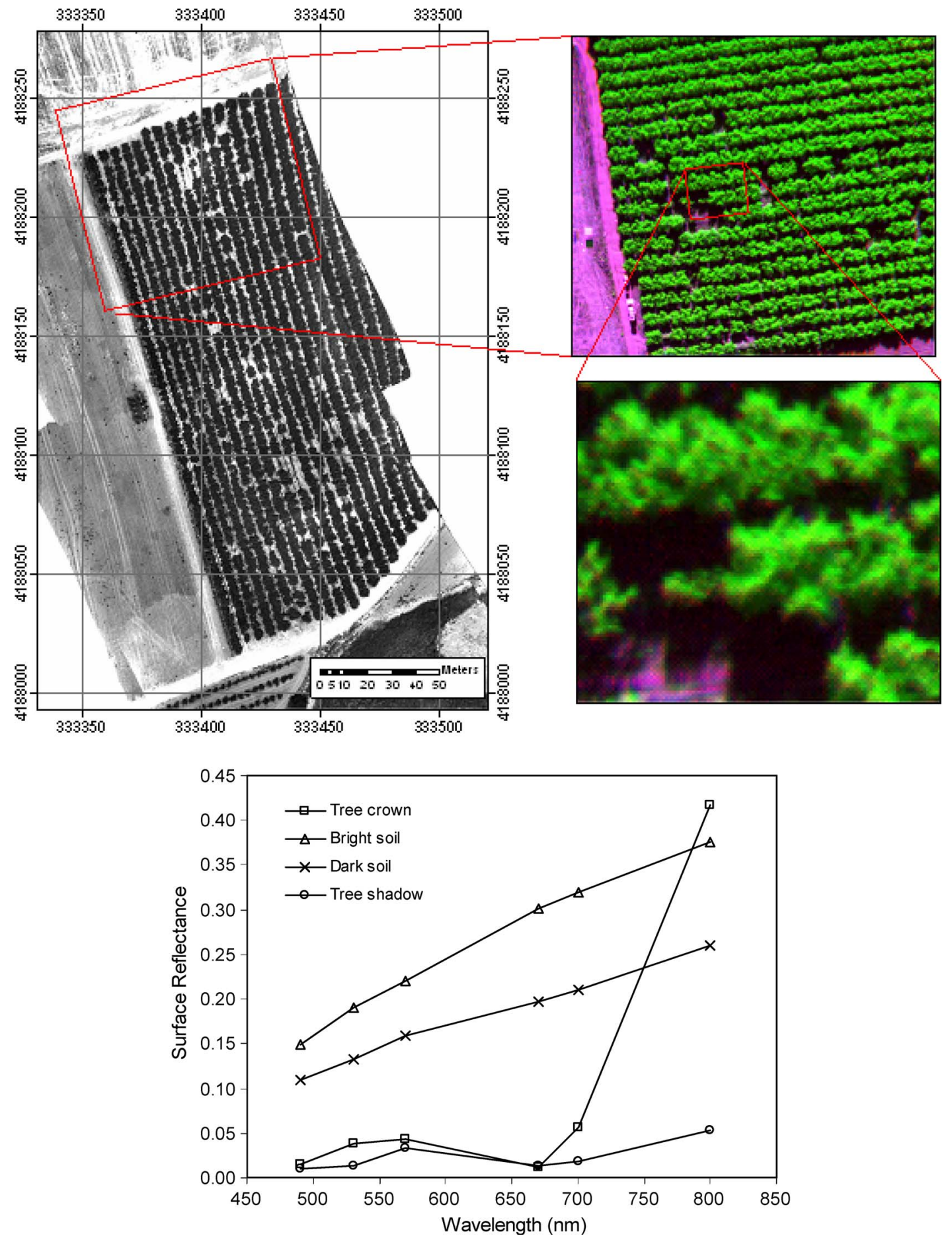

Fig. 10. (a) Multispectral orthomosaic collected over a peach orchard at 20-cm spatial resolution. The image on the top left is a false color zoom of the study site, and showing on the bottom right image is the detailed view of the tree crowns at full resolution. (b) Spectral reflectance extracted from different targets from the image mosaic.

conditions. For instance, a bias of more than $4 \mathrm{~K}$ can occur under high relative humidity and low temperatures.

Due to the camera wide FOV $\left(40^{\circ}\right)$ and the helicopter tilt angles, the path lengths for each pixel had to be corrected. Assuming an image collected at a given time, the principal point of the camera $P_{o}$ is located at the coordinates $\left(X_{o}, Y_{o}, Z_{o}\right)$ with an attitude of $(\varphi, \omega, \kappa)$ which are pitch, roll, and yaw, respectively. An approximation of these values was extracted from the autopilot telemetry, and the calibration for pixel-to-sensor variations across the image was conducted. For a given point $P$ with ground coordinates $\left(X_{p}, Y_{p}, Z_{p}\right)$, the image coordinates of the corresponding pixel reduced to the principal point and with the effects of lens distortion $\left(x_{p}^{\prime}, y_{p}^{\prime}\right)$ were estimated using the collinearity

$$
\left[\begin{array}{c}
x_{p}^{\prime} \\
y_{p}^{\prime} \\
-c
\end{array}\right]=\frac{1}{\lambda_{p}} M\left[\begin{array}{c}
X_{p}-X_{o} \\
Y_{p}-Y_{o} \\
Z_{p}-Z_{o}
\end{array}\right]
$$




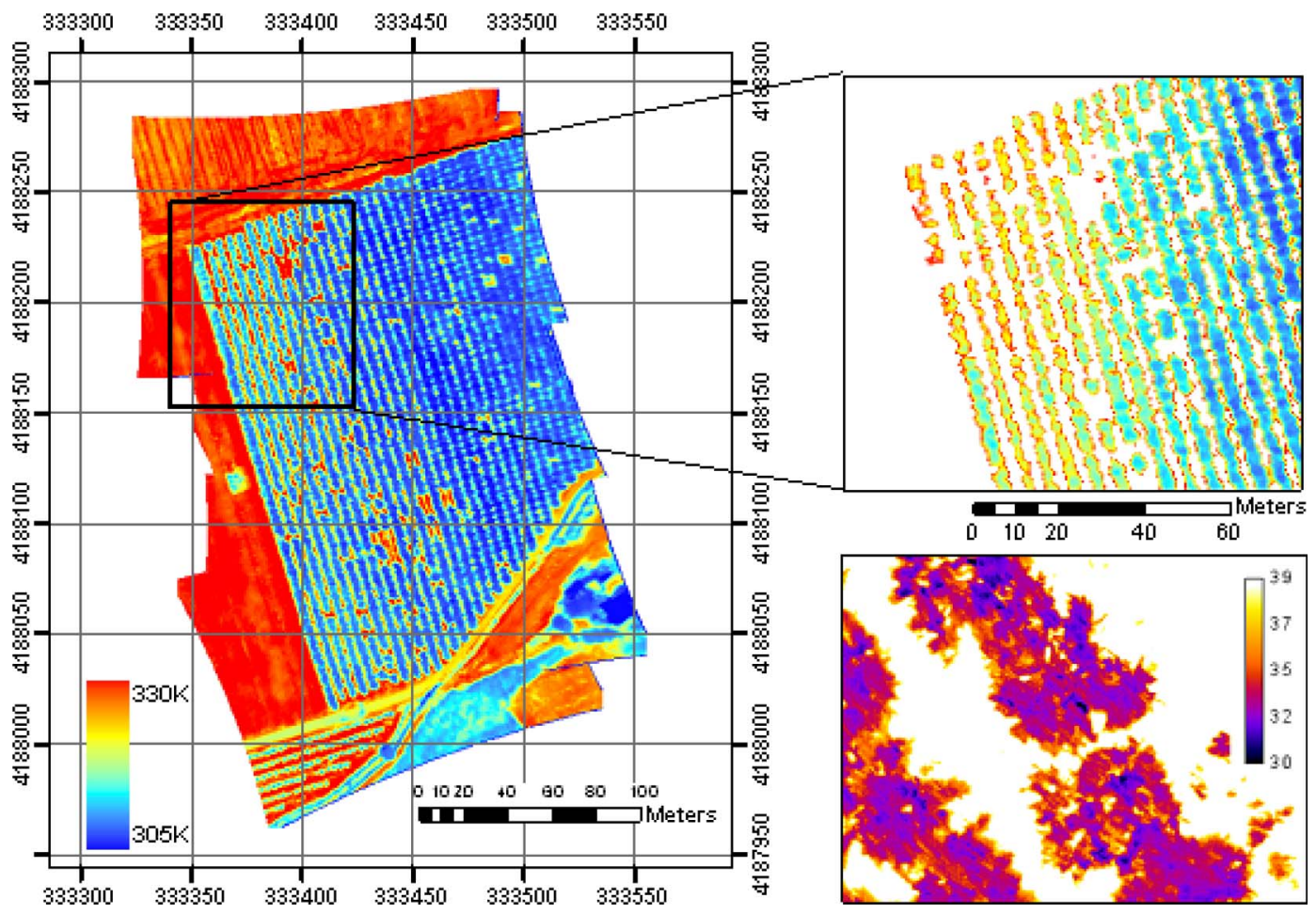

Fig. 11. Thermal orthomosaic obtained from the UAV over the peach orchard at 40-cm resolution. The zoomed image on the top shows the water stressed trees (warmer, in red and yellow) as compared with the fully irrigated trees (blue). The bottom right image shows a low-altitude image where within-crown thermal variability is observed.

where $M$ is the rotation matrix obtained from the attitude angles, $c$ is the focal distance, and $\lambda_{p}$ is the associated scale factor.

Equation (7) can be reversed, and therefore, the ground coordinates for a given pixel can be calculated with (8) and (9) if the center of projection of the image $\left(P_{o}\right)$ and ground elevation are known, and the terrain is considered flat

$$
\begin{aligned}
X_{p} & =\lambda_{p}\left\lfloor m_{11} x_{p}^{\prime}+m_{21} y_{p}^{\prime}+m_{31}(-c)\right\rfloor+X_{o} \\
Y_{p} & =\lambda_{p}\left\lfloor m_{12} x_{p}^{\prime}+m_{22} y_{p}^{\prime}+m_{32}(-c)\right\rfloor+Y_{o} \\
Z_{p} & =\lambda_{p}\left\lfloor m_{13} x_{p}^{\prime}+m_{23} y_{p}^{\prime}+m_{33}(-c)\right\rfloor+Z_{o}
\end{aligned}
$$

where

$$
\lambda_{p}=\frac{m_{12} x_{p}^{\prime}+m_{23} y_{p}^{\prime}-m_{33} c}{Z_{p}-Z_{o}} .
$$

Since $Z_{p}-Z_{o}$ can be estimated as the mean altitude above ground level for a flat terrain, $X_{p}$ and $Y_{p}$ can be solved. The distance to the ground point can be expressed as

$$
D_{o-p}=\sqrt{\left(X_{o}-X_{p}\right)^{2}+\left(Y_{o}-Y_{p}\right)^{2}+\left(Z_{o}-Z_{p}\right)^{2}} .
$$

We used this methodology to estimate the sensor-to-pixel distance across the image, needed to generate a transmittance and thermal radiation map for each image. The effect of this correction is shown in Fig. 7(b).

A flight campaign was conducted by measuring simultaneously the surface temperature with a thermal gun (LaserSight, Optris, Germany) over three different surfaces: soil, white, and black targets (Fig. 8). The RMSE before calibration was $3.44 \mathrm{~K}$, which was reduced to $0.89 \mathrm{~K}$ after atmospheric correction.

\section{Automatic Mosaicking With Aerotriangulation Methods}

GPS and INS systems used along with photogrammetric methods enable the estimation of direct platform orientation without ground control points [73], [74]. Position and attitude were extracted directly from the autopilot AHRS with a time resolution of $0.05 \mathrm{~s}$. The lack of precise synchronization between the autopilot time (based on GPS time) and image triggering prevented the estimation of the direct platform orientation. In the case of the thermal camera, time and mission time were reset before each flight campaign, acquiring one image every $2 \mathrm{~s}$. This method enabled the estimation of an approximate $\mathrm{EO}$ for the projection center of each image.

Calibrated images were imported into Leica Photogrammetric Suite (Leica Geosystems, Switzerland) together with the EO file in plain text format. Images taken during UAV turns and outside the study sites were removed. The low platform speed $(30 \mathrm{~km} / \mathrm{h})$ and low altitude $(200 \mathrm{~m})$ of the UAV generated a high degree of overlapping among images along the flight direction (80\%-90\% overlap). The high overlapping obtained was very important to ensure that only the most nadir part of each image was considered to avoid viewing directional effects on both multispectral and thermal imagery. Fig. 9 shows a study area with red rectangles representing the image footprint over the orange tree study site, with the yellow rectangle indicating the overlapping area of a stereo pair. Once the model was created and configured, tie points were generated automatically, and a minimum number of ground control and check points were manually measured on the corresponding images. Aerotriangulation was calculated, and the results were revised until the rms error of the ground control points was below the estimated pixel 
resolution. Finally, an orthomosaic could be generated using an existing DTM or a uniform terrain height (Fig. 10).

\section{E. Study Sites}

During the validation stage of the remote sensing UAV system, a total of three study sites were selected to conduct airborne campaigns with onboard remote sensing instruments to validate the ability for biophysical parameter retrieval. The detection of water stress in different crops was conducted on study sites with plant water status differences.

A commercial peach orchard near Cordoba (Spain) was studied to assess if water stress levels could be detected with highresolution thermal imagery acquired from the UAV platform. The field studied had part under regulated deficit irrigation (RDI) [75], while the other part had ample water supply.

Another study was carried out over a corn variety test field to show the performance of the multispectral camera over herbaceous crops and the use of narrowband vegetation indices to detect crop water status. The field was divided into 72 individual plots $2.4 \times 10 \mathrm{~m}$ in size, comprising 24 varieties replicated three times. The field was last irrigated in midJune and was under water stress in July at the time of flight acquisitions. The study included measurements of stomatal conductance and leaf water potential in six different cultivars, taken four times during the day and coincident with the four flights that were undertaken on the 6th of July.

Finally, an olive variety test orchard was flown to assess the capability of the multispectral imagery to retrieve biophysical parameters such as chlorophyll $\mathrm{a}+\mathrm{b}$ content and LAI over discontinuous crops at the tree level. The orchard was very heterogeneous as compared to a commercial olive orchard because of the large number of varieties that had been planted.

\section{Results AND Discussion}

Results from the 12 airborne campaigns flown over the peach orchard in July 2007 at solar noon showed thermal variations over the entire area due to variation in irrigation level. As expected, the canopies of trees under RDI were clearly warmer than those of fully irrigated trees (Fig. 11), with an average difference of $4.3 \mathrm{~K}$ between trees supplied with full ET and RDI trees. This experiment demonstrated that low-cost thermal imagers onboard unmanned vehicles successfully estimated the absolute surface temperature through radiometric calibration and atmospheric correction methods, enabling the detection of tree water stress levels.

Results on the corn field experiment flown four times on June 6, 2007 with multispectral [Fig. 12(a)] and thermal cameras demonstrated that spectral reflectance was successfully calibrated as compared with ground ASD measurements, yielding $1.17 \%$ RMSE. The mean spectral reflectance and temperature extracted for each variety plot showed a relationship between the vegetation index proposed as an indicator of stress (PRI) and plot temperature as an indicator of canopy conductance. The reflectance spectra in the PRI region between 520 and $580 \mathrm{~nm}$ showed a positive slope between 530 and $570 \mathrm{~nm}$ [Fig. 12(b)], typical of plants under water stress [64]. The phys-

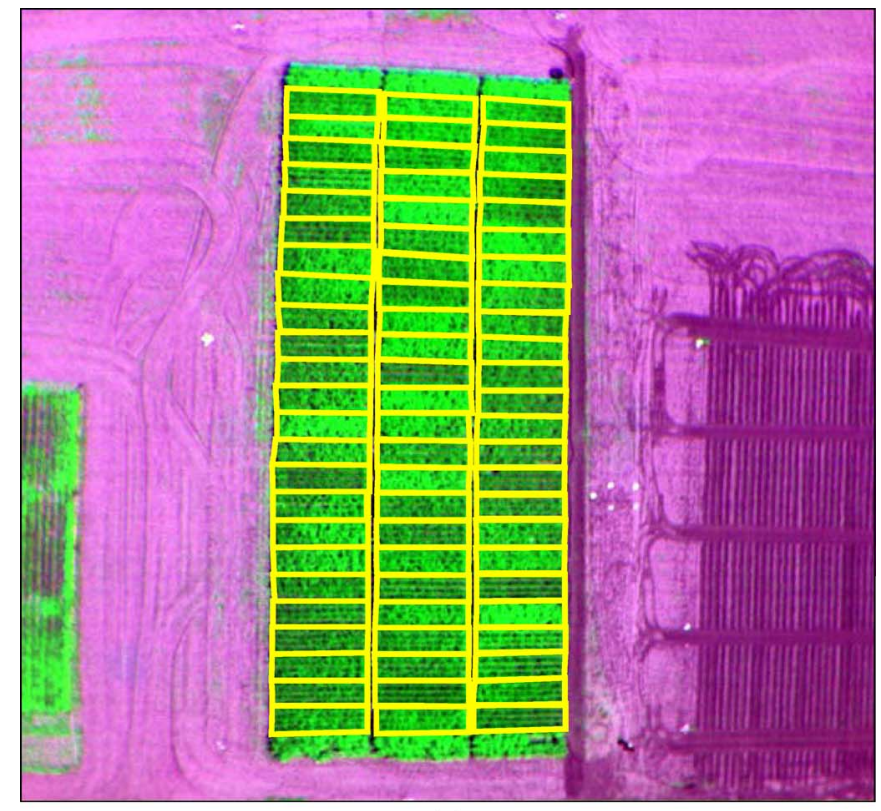

(a)

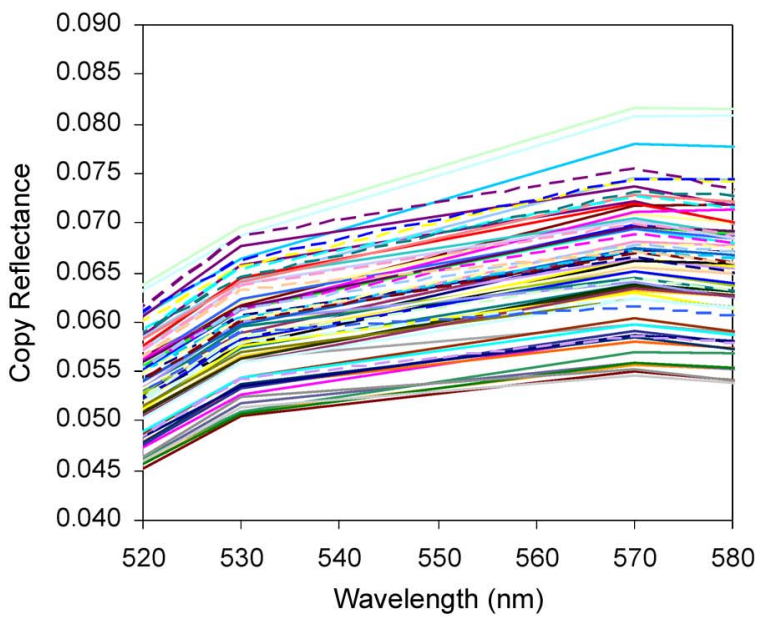

(b)

Fig. 12. (a) Corn plots of different varieties imaged by the MCA- 6 camera onboard the UAV system. (b) Extracted reflectance spectra in the 530-570-nm spectral region for the calculation of the PRI index used for stress detection.

iological indicator of stress (PRI) and the canopy temperature for each plot were constrained to NDVI values ranging between 0.76 and 0.78 to minimize structural and soil effects on the indices. The results shown in Fig. 13(a) prove the lack of relationship between NDVI and canopy temperature for such a small range of NDVI values. These results suggest that the differences in plot temperature were due to canopy conductance and water stress levels, but not due to structural parameters or differences in ground coverage. On the other hand, physiological indicators of stress such as PRI and canopy temperature showed a good relationship within the same NDVI levels $\left(r^{2}=0.69\right)$ [Fig. 13(b)], suggesting that both visible (400-700-nm spectral range, PRI) and thermal regions $(7.5-13 \mu \mathrm{m})$ were able to detect crop water stress levels from the low-cost UAV platform.

One important application in plant breeding would be to use the canopy temperature measurements from the UAV platform for screening different genotypes for drought avoidance. This 


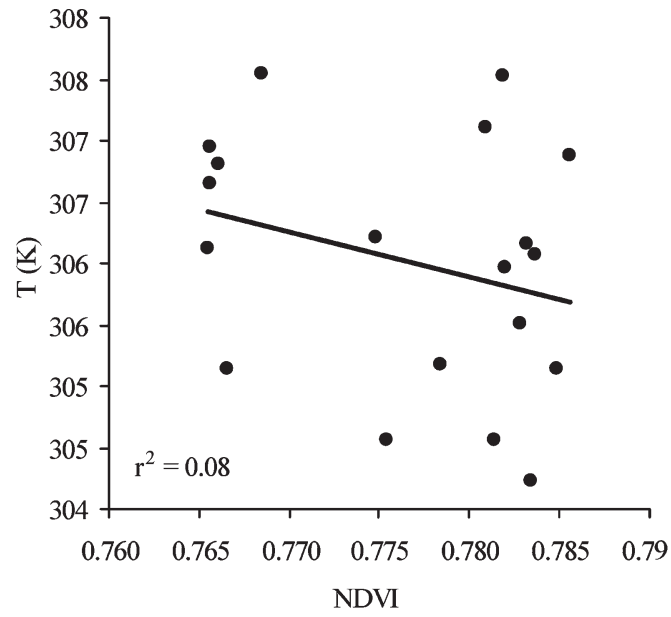

(a)

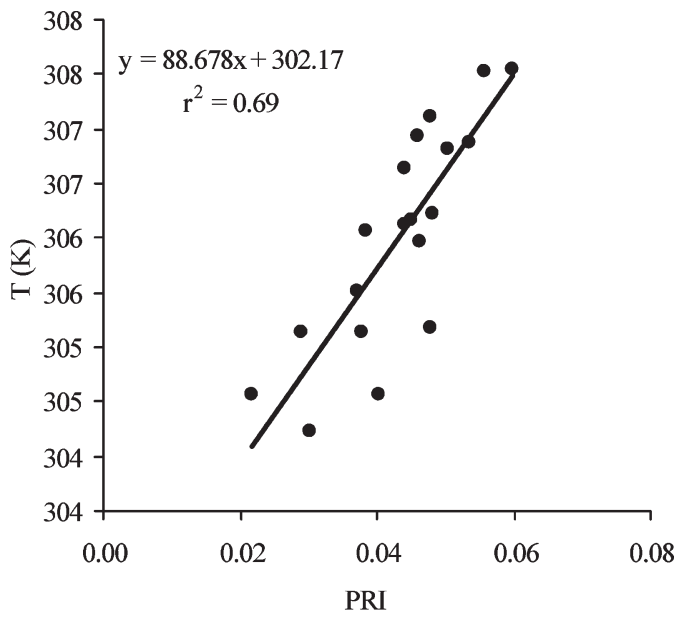

(b)

Fig. 13. (a) Relationships obtained between the FLIR thermal camera and spectral indices calculated from the multispectral camera over corn blocks under same NDVI levels for (a) block T versus NDVI and (b) block T versus PRI. These plots demonstrate the sensitivity of PRI as indicator of water stress.

(a)

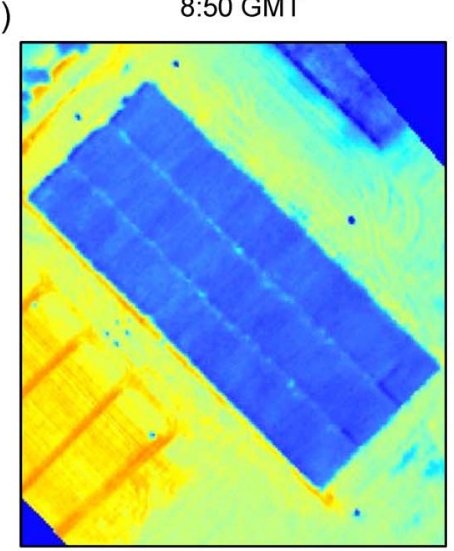

(c)

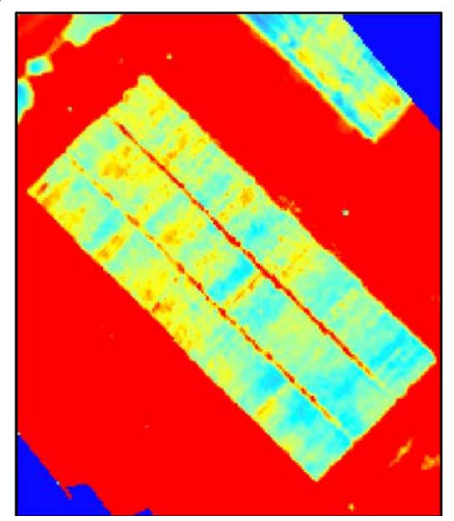

(b)

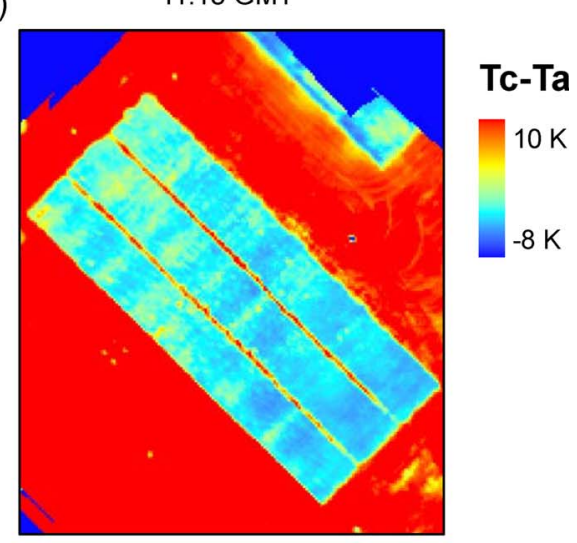

(d)

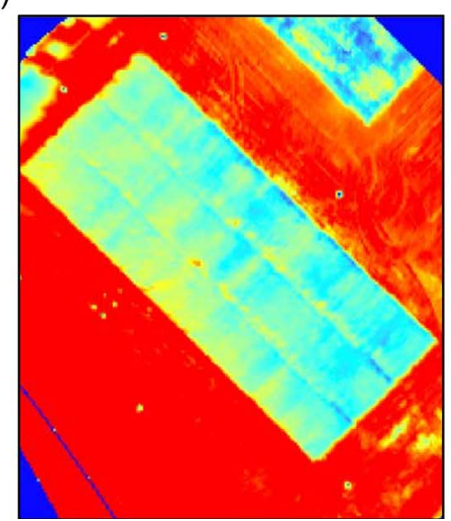

Fig. 14. Thermal images acquired over the corn field at 0.4-m pixel resolution showing the $T_{c}-T_{a}$ changes at four different times of day. The greatest thermal variability between corn variety plots is obtained at midday, continuing during the afternoon.

approach was successfully used in wheat sometime ago [42] and has been tried in other breeding programs (i.e., [43]), but it has been limited by operational difficulties associated with the use of sensors at ground level. The results obtained from the flights over the corn variety trial illustrate the potential of this platform for genotype screening. Fig. 14 shows the genotypic variability in canopy temperatures measured from the UAV at four different times on the 6th of July. On that day, there was significant water stress, as indicated by midday leaf water potential values that varied between -1.3 and $-1.5 \mathrm{MPa}$. Canopy temperatures in the morning were quite uniform among corn cultivars, but they started to diverge as the day went on. Fig. 15 shows the genotypic differences between two cultivars that had very similar NDVI but that clearly differed in their stress response. In the morning, both canopies were cooler than the air, and the stomatal conductance values were quite 


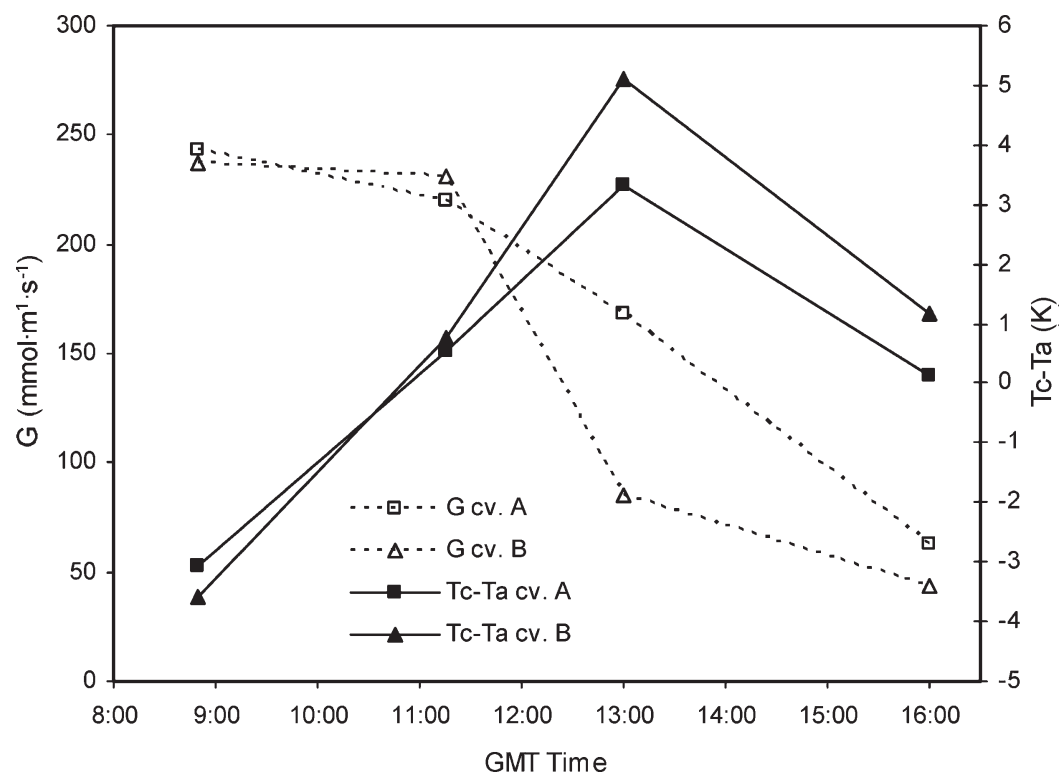

Fig. 15. Diurnal stomatal conductance $(G)$ and canopy $T_{c}-T_{a}$ acquired from two corn cultivars. Differences found in the stomatal conductance at noon for both cultivars yielded variations that could be tracked by the thermal imagery.

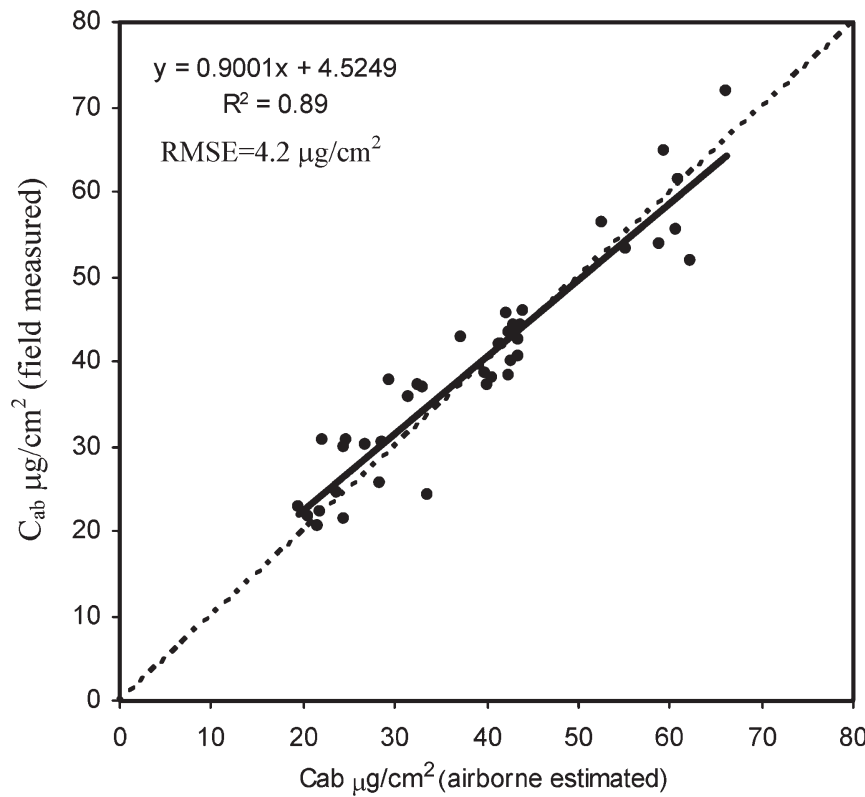

Fig. 16. Ground truth chlorophyll content $\left(C_{\mathrm{ab}}\right)$ measured in olive and peach trees compared with UAV-estimated $C_{\text {ab }}$ through the TCARI/OSAVI index and predictive algorithms.

high, indicating high transpiration rates. As water stress set in, the stomata close and canopy temperatures increase. By early afternoon, the time of maximum evaporative demand, the stomata are quite closed and the canopies are warmest. However, one genotype is cooler than the other and has higher stomatal conductance and, hence, transpiration (Fig. 15). It should be emphasized that such genotypic differences were detected in our flights among commercial varieties, while differences of greater magnitude should be expected among breeding lines.

The estimation of chlorophyll concentration from the multispectral instrument onboard the UAV used the Mahalanois supervised classification method to extract pure crown regions of interest for each individual tree in the olive and peach
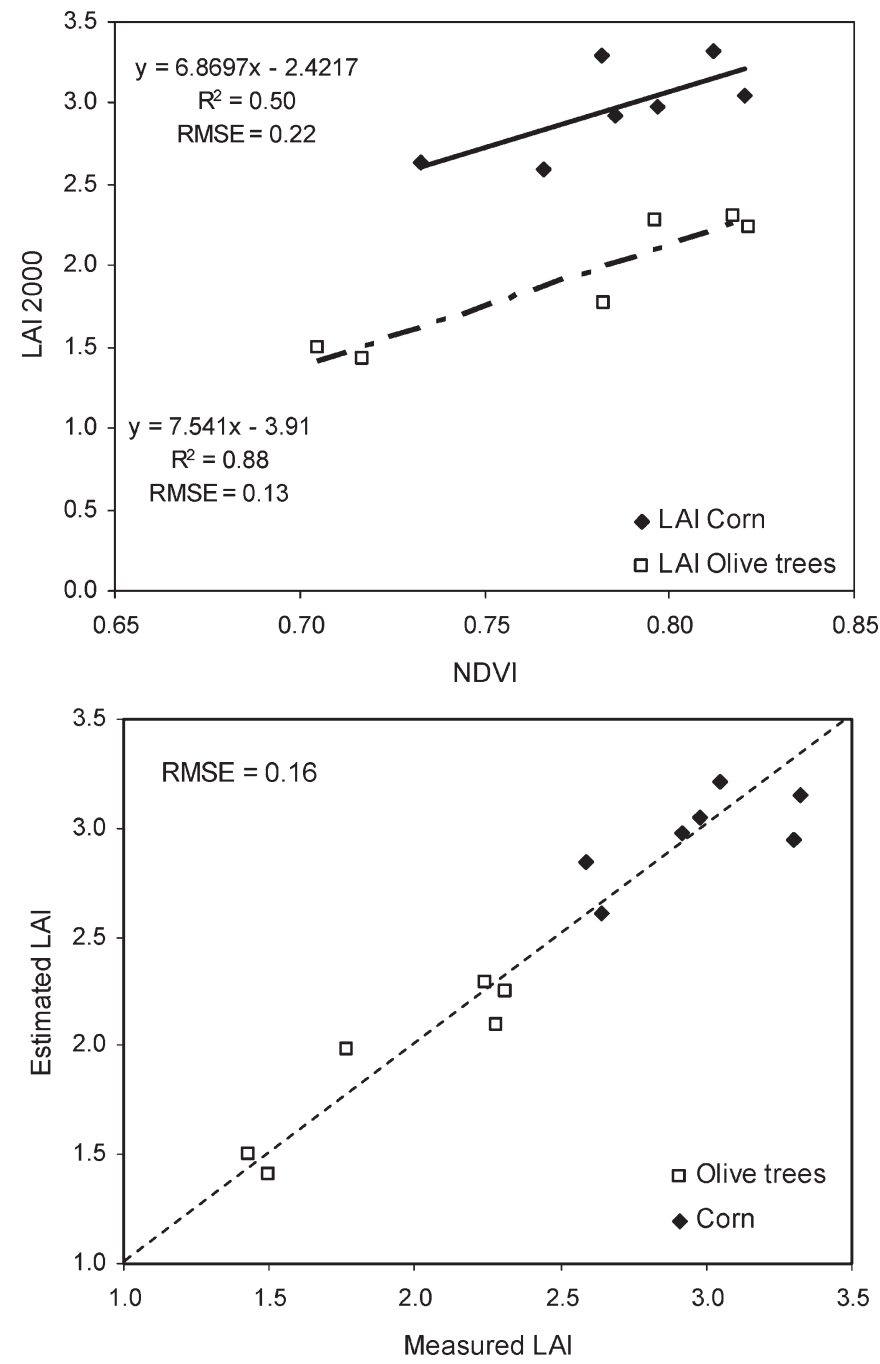

Fig. 17. (a) Relationships between NDVI and LAI for corn and olive trees. (b) Validation of LAI estimates from the UAV versus ground truth LAI measurements. 
(a)

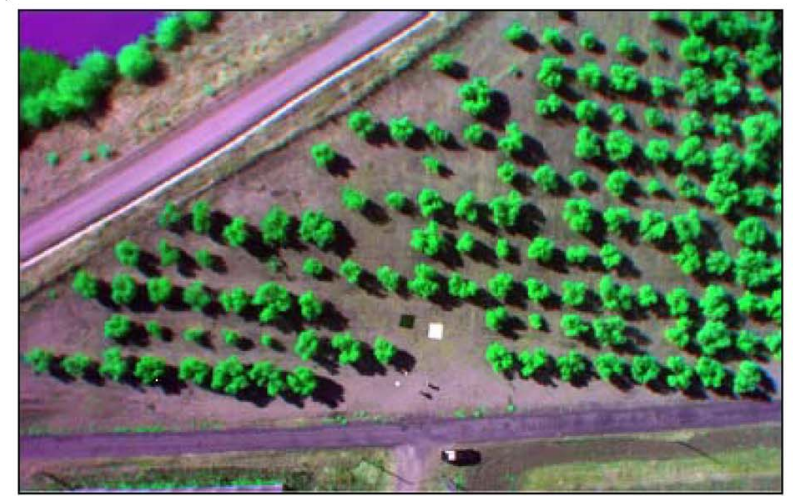

(b)

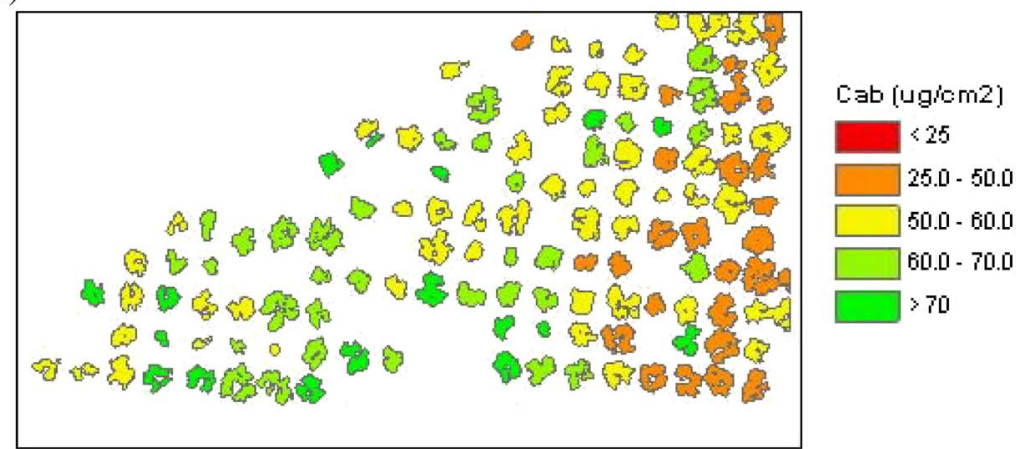

(c)

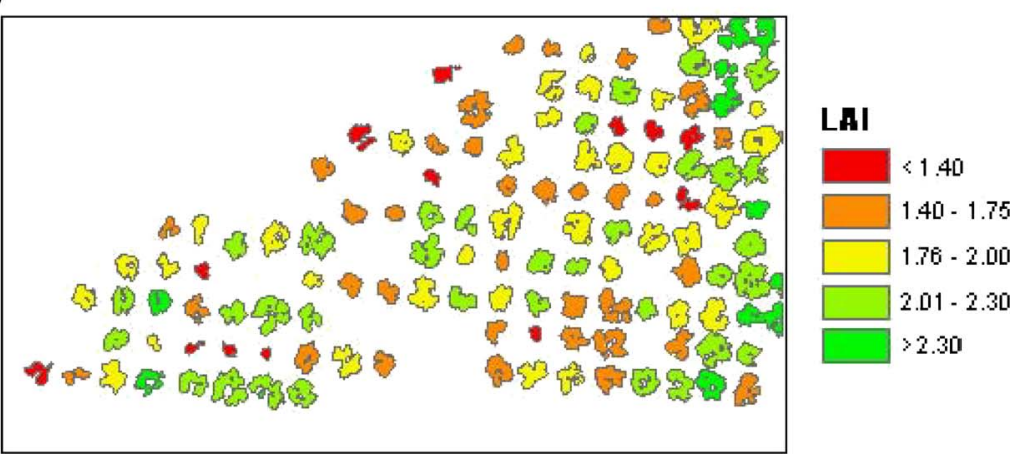

Fig. 18. Sample multispectral imagery acquired over an olive orchard with the MCA-6 camera at 10-nm FWHM bandwidths onboard the UAV platform (0.15-m spatial resolution), showing the chlorophyll content and LAI maps obtained.

orchards. The TCARI/OSAVI chlorophyll index calculated from the mean crown spectra extracted from the imagery successfully estimated chlorophyll $a+b$ concentration. A comparison between field-measured $C_{\mathrm{ab}}$ and airborne-estimated $C_{\mathrm{ab}}$ yielded an RMSE of $4.2 \mu \mathrm{g} / \mathrm{cm}^{2}$ and $r^{2}=0.89$ (Fig. 16), demonstrating the capabilities of the multispectral MCA-6 camera onboard the UAV platform for estimating chlorophyll content at the crown level.

NDVI and LAI relationships were studied for olive and corn [Fig. 17(a)]. In the case of olive trees, NDVI was calculated for each individual tree using the mean spectra from the same regions of interest that were used for chlorophyll content estimation. For the corn field, NDVI was calculated using the average spectrum from each block. In both cases, NDVI correlated with the ground truth LAI $\left(r^{2}=0.5\right.$ for corn; $r^{2}=$ 0.88 for olive trees). The lower correlation in the corn field is probably related to the differential responses of corn canopy architecture to water deficits, as the leaves of some cultivars had rolled and become more erected to reduce plant radiation load. The resulting RMSE for the estimated LAI was 0.16 [Fig. 17(b)]. From the extracted crown spectra in the olive orchard [Fig. 18(a)], maps of mean chlorophyll $a+b$ content [Fig. 18(b)] and LAI [Fig. 18(c)] were generated using the relationships described earlier. The resulting maps show the spatial variability of chlorophyll content and LAI over the orchard obtained from the UAV system.

\section{CONCLUSION}

This paper demonstrated the ability to generate quantitative remote sensing products by means of a helicopter-based UAV equipped with COTS inexpensive thermal and multispectral imaging sensors. The low cost and operational flexibility, along with the high spatial, spectral, and temporal resolutions provided at high turnaround times, make this platform suitable for a number of applications, including precision farming or 
irrigation scheduling, where time-critical management is required. The laboratory and field calibration methods provided a six-band 10-nm FWHM multispectral imagery with RMSE of $1.17 \%$ in ground reflectance and less than $0.2-\mathrm{m}$ spatial resolution. For the thermal camera, the atmospheric effects on transmittance and atmospheric thermal path radiation were found to be very important even for low-altitude flights where errors higher than $4 \mathrm{~K}$ could be achieved if those effects were not considered. Atmospheric correction methods based on MODTRAN radiative transfer model showed the successful estimation of surface temperature images of $40-\mathrm{cm}$ spatial resolution, yielding RMSE $<1 \mathrm{~K}$.

Appropriate bandset configurations selected for the multispectral camera enabled the calculation of several traditional narrowband vegetation indices (NDVI, TCARI/OSAVI, and PRI) which were linked to biophysical parameters using quantitative methods based on physical approaches such as PROSPECT, SAILH, and FLIGHT models. The validation results obtained for the estimation of LAI in corn $\left(r^{2}=0.5\right)$ and olive trees $\left(r^{2}=0.88\right)$, chlorophyll $\mathrm{a}+\mathrm{b}$ concentration $\left(\mathrm{RMSE}=4.2 \mu \mathrm{g} / \mathrm{cm}^{2} ; r^{2}=0.89\right)$, and the relationships between canopy temperature and stomatal conductance in corn revealed results comparable to those obtained in similar experimental campaigns using current state-of-the-art imaging spectrometer of multiband sensors onboard manned aircraft [25], [36], [40] and open way to the use of this platform as a screening tool in drought resistance breeding programs. The PRI used for stress detection demonstrated on imagery acquired over corn fields that the vegetation index was well related with canopy temperature $\left(r^{2}=0.69\right)$, suggesting its use as a good indicator of water stress.

Photogrammetric techniques were required to register the frame-based imagery to map coordinates. Cameras were geometrically characterized with their intrinsic parameters, achieving location errors within one pixel size. These techniques, along with the position and attitude data gathered from the autopilot, enabled the generation of large mosaics semiautomatically with the minimum use of ground control points. The main limitations encountered for this platform were the endurance $(20 \mathrm{~min})$ and the low flight speed $(30 \mathrm{~km} / \mathrm{h})$, limiting the productivity to 70 hectares per flight. However, the operating flexibility of vertical takeoff and landing platforms make it ideal for experimental purposes. For large commercial agricultural applications, where hundreds of hectares should be monitored quickly, the use of fixed-wing UAVs with enhanced endurance, moderate cruise speeds, and easier operation would be preferred to rotary-wing aircrafts. UAV-based remote sensing platforms are expected to fill the gap in the extended use of remote sensing in agriculture. With the cost reduction of autopilots and imaging sensors, it will soon become an invaluable tool to monitor the water status of crops, with the aim of achieving Jackson's envision in the 1970s for real-time irrigation scheduling and crop monitoring.

\section{ACKNOWLEDGMENT}

The authors would like to thank the UAV Navigation and Tetracam Inc. for the technical support for accommodating changes in the firmware for MCA-6 adapted to UAV operation. The authors would also like to thank V. González, M. Morales, C. Ruz, G. Sepulcre-Cantó, D. Notario, M. Guillén, C. Trapero, and I. Calatrava for measurements and technical support in field campaigns and also A. Vera and M. Ruiz Bernier for being the UAV human backup pilots. Finally, the authors would like to thank Bioiberica for the in-kind support through Project PETRI PET2005-0616.

\section{REFERENCES}

[1] H. Erol and F. Akdeniz, "A multispectral classification algorithm for classifying parcels in an agricultural region," Int. J. Remote Sens., vol. 17, no. 17 , pp. 3357-3371, Nov. 1996.

[2] A. Grignetti, R. Salvatori, R. Casacchia, and F. Manes, "Mediterranean vegetation analysis by multi-temporal satellite sensor data," Int. J. Remote Sens., vol. 18, no. 6, pp. 1307-1318, Apr. 1997.

[3] M. Pax-Lenney and C. E. Woodcock, "The effect of spatial resolution on the ability to monitor the status of agricultural lands," Remote Sens. Environ., vol. 61, no. 2, pp. 210-220, Aug. 1997.

[4] J. G. P. W. Clevers, "A simplified approach for yield prediction of sugar beet based on optical remote sensing data," Remote Sens. Environ., vol. 61, no. 2, pp. 221-228, Aug. 1997.

[5] M. Moran, S. Maas, and P. Pinter, Jr., "Combining remote sensing and modeling for estimating surface evaporation and biomass production," Remote Sens. Rev., vol. 12, pp. 335-353, 1995.

[6] M. S. Rasmussen, "Assessment of millet yields and production in northern Burkina-Faso using integrated NDVI from the AVHRR," Int. J. Remote Sens., vol. 13, no. 18, pp. 3431-3442, Dec. 1992.

[7] C. J. Tucker, B. N. Holben, J. H. Elgin, and J. Mcmurtrey, "Relationship of spectral data to grain-yield variation," Photogramm. Eng. Remote Sens., vol. 46, pp. 657-666, 1980.

[8] T. M. Blackmer, J. S. Schepers, and G. E. Varvel, "Light reflectance compared with other nitrogen stress measurements in corn leaves," Agron. J., vol. 86, no. 6, pp. 934-938, 1994.

[9] P. Boissard, J. G. Pointel, and P. Huet, "Reflectance, green leaf area index and ear hydric status of wheat from anthesis until maturity," Int. J. Remote Sens., vol. 14, no. 14, pp. 2713-2729, Sep. 1993.

[10] J. G. P. W. Clevers, C. Buker, H. J. C. van Leeuwen, and B. A. M. Bouman, "A framework for monitoring crop growth by combining directional and spectral remote sensing information," Remote Sens. Environ., vol. 50, no. 2, pp. 161-170, Nov. 1994.

[11] M. B. Potdar, "Sorghum yield modeling based on crop growth-parameters determined from visible and near-IR channel NOAA AVHRR data," Int. J. Remote Sens., vol. 14, pp. 895-905, 1993.

[12] J. Everitt, G. Anderson, D. Escobar, M. Davis, N. Spencer, and R. Andrascik, "Use of remote sensing for detecting and mapping leafy spurge (Euphorbia esula)," Weed Technol., vol. 9, no. 3, pp. 599-609, 1995

[13] E. Underwood, S. Ustin, and D. DiPietro, "Mapping nonnative plants using hyperspectral imagery," Remote Sens. Environ., vol. 86, no. 2, pp. 150-161, Jul. 2003.

[14] G. Anderson, J. Everitt, A. Richardson, and D. Escobar, "Using satellite data to map false broomweed (Ericameria austrotexana) infestations on South Texas rangelands," Weed Technol., vol. 7, pp. 865-871, 1993.

[15] T. J. Malthus and A. C. Madeira, "High resolution spectroradiometry: Spectral reflectance of field bean leaves infected by Botrytis Fabae," Remote Sens. Environ., vol. 45, no. 1, pp. 107-116, Jul. 1993.

[16] M. L. Adams, W. D. Philpot, and W. A. Norvell, "Yellowness index: An application of spectral second derivatives to estimate chlorosis of leaves in stressed vegetation," Int. J. Remote Sens., vol. 20, no. 18, pp. 3663-3675, Dec. 1999.

[17] M. L. Adams, W. A. Norvell, W. D. Philpot, and J. H. Peverly, "Toward the discrimination of manganese, zinc, copper, and iron deficiency in "Bragg" soybean using spectral detection methods," Agron. J., vol. 92, no. 2, pp. 268-274, 2000.

[18] P. H. Sampson, P. J. Zarco-Tejada, G. H. Mohammed, J. R. Miller, and T. L. Noland, "Hyperspectral remote sensing of forest condition: Estimating chlorophyll content in tolerant hardwoods," For. Sci., vol. 49, no. 3, pp. 381-391, Jun. 2003.

[19] P. Zarco-Tejada, A. Berjón, R. López-Lozano, J. Miller, P. Martín, V. Cachorro, M. González, and A. de Frutos, "Assessing vineyard condition with hyperspectral indices: Leaf and canopy reflectance simulation in 
a row-structured discontinuous canopy," Remote Sens. Environ., vol. 99, no. 3, pp. 271-287, Nov. 2005.

[20] P. Martín, P. Zarco-Tejada, M. González, and A. Berjón, "Using hyperspectral remote sensing to map grape quality in "Tempranillo" vineyards affected by iron deficiency chlorosis," Vitis, vol. 46, no. 1, pp. 7-14, 2007.

[21] M. S. Moran, Y. Inoue, and E. M. Barnes, "Opportunities and limitations for image-based remote sensing in precision crop management," Remote Sens. Environ., vol. 61, no. 3, pp. 319-346, Sep. 1997.

[22] Y. Yamaguchi, A. B. Kahle, H. Tsu, T. Kawakami, and M. Pniel, "Overview of advanced spaceborne thermal emission and reflection radiometer (ASTER)," IEEE Trans. Geosci. Remote Sens., vol. 36, no. 4, pp. 1062-1071, Jul. 1998.

[23] P. J. Zarco-Tejada, J. R. Miller, T. L. Noland, G. H. Mohammed, and P. H. Sampson, "Scaling-up and model inversion methods with narrowband optical indices for chlorophyll content estimation in closed forest canopies with hyperspectral data," IEEE Trans. Geosci. Remote Sens., vol. 39, no. 7, pp. 1491-1507, Jul. 2001.

[24] I. Moorthy, J. R. Miller, T. L. Noland, U. Nielsen, and P. J. Zarco-Tejada, "Chlorophyll content estimation of boreal conifers using hyperspectral remote sensing," in Proc. IEEE IGARSS_Learning From Earth's Shapes and Sizes, 2003, vol. I-VII, pp. 2568-2570.

[25] P. Zarco-Tejada, J. Miller, A. Morales, A. Berjón, and J. Agüera, "Hyperspectral indices and model simulation for chlorophyll estimation in open-canopy tree crops," Remote Sens. Environ., vol. 90, no. 4, pp. $463-$ 476, Apr. 2004.

[26] P. Zarco-Tejada, J. Miller, J. Harron, B. Hu, T. Noland, N. Goel, G. Mohammed, and P. Sampson, "Needle chlorophyll content estimation through model inversion using hyperspectral data from boreal conifer forest canopies," Remote Sens. Environ., vol. 89, no. 2, pp. 189-199, Jan. 2004.

[27] D. A. Roberts, R. O. Green, and J. B. Adams, "Temporal and spatial patterns in vegetation and atmospheric properties from AVIRIS," Remote Sens. Environ., vol. 62, no. 3, pp. 223-240, Dec. 1997.

[28] S. L. Ustin, D. A. Roberts, J. Pinzón, S. Jacquemoud, M. Gardner, G. Scheer, C. M. Castañeda, and A. Palacios-Orueta, "Estimating canopy water content of chaparral shrubs using optical methods," Remote Sens. Environ., vol. 65, no. 3, pp. 280-291, Sep. 1998.

[29] L. Serrano, S. L. Ustin, D. A. Roberts, J. A. Gamon, and J. Peñuelas, "Deriving water content of chaparral vegetation from AVIRIS data," Remote Sens. Environ., vol. 74, no. 3, pp. 570-581, Dec. 2000.

[30] Y. B. Cheng, D. Riano, P. J. Zarco-Tejada, and S. L. Ustin, "Canopy water content estimates with AVIRIS imagery and MODIS reflectance products," in Proc. SPIE-Remote Sensing and Modeling of Ecosystems for Sustainability III, 2006, vol. 6298, p. 629809.

[31] Y. B. Cheng, P. J. Zarco-Tejada, D. Riano, C. A. Rueda, and S. L. Ustin, "Estimating vegetation water content with hyperspectral data for different canopy scenarios: Relationships between AVIRIS and MODIS indexes," Remote Sens. Environ., vol. 105, no. 4, pp. 354-366, Dec. 2006.

[32] D. Sims and J. Gamon, "Relationships between leaf pigment content and spectral reflectance across a wide range of species, leaf structures and developmental stages," Remote Sens. Environ., vol. 81, no. 2/3, pp. 337354, Aug. 2002.

[33] S. Jacquemoud, S. Ustin, J. Verdebout, G. Schmuck, G. Andreoli, and B. Hosgood, "Estimating leaf biochemistry using the PROSPECT leaf optical properties model," Remote Sens. Environ., vol. 56, no. 3, pp. 194-202, Jun. 1996.

[34] T. Fourty and F. Baret, "Vegetation water and dry matter contents estimated from top-of-the-atmosphere reflectance data: A simulation study," Remote Sens. Environ., vol. 61, no. 1, pp. 34-45, Jul. 1997.

[35] D. Riano, P. Vaughan, E. Chuvieco, P. Zarco-Tejada, and S. L. Ustin, "Estimation of fuel moisture content by inversion of radiative transfer models to simulate equivalent water thickness and dry matter content: Analysis at leaf and canopy level," IEEE Trans. Geosci. Remote Sens., vol. 43, no. 4, pp. 821-826, Apr. 2005.

[36] D. Haboudane, J. Miller, E. Pattey, P. Zarco-Tejada, and I. Strachan, "Hyperspectral vegetation indices and novel algorithms for predicting green lai of crop canopies: Modeling and validation in the context of precision agriculture," Remote Sens. Environ., vol. 90, no. 3, pp. 337-352, Apr. 2004.

[37] R. D. Jackson, R. J. Reginato, and S. B. Idso, "Wheat canopy temperature: A practical tool for evaluating water requirements," Water Resour. Res., vol. 13, no. 3, pp. 651-656, 1977.

[38] R. D. Jackson, S. B. Idso, R. J. Reginato, and P. J. Pinter, "Canopy temperature as a crop water stress indicator," Water Resour. Res., vol. 17, no. 4, pp. 1133-1138, 1981.

[39] G. Sepulcre-Cantó, P. J. Zarco-Tejada, J. A. Sobrino, J. C. Jiménez-Muñoz, and F. J. Villalobos, "Spatial variability of crop water stress in an olive grove with high-spatial thermal remote sensing imagery," in Proc. Precision Agric., 2005, pp. 267-272.

[40] G. Sepulcre-Cantó, P. Zarco-Tejada, J. Jiménez-Muñoz, J. Sobrino, E. de Miguel, and F. Villalobos, "Detection of water stress in an olive orchard with thermal remote sensing imagery," Agric. For. Meteorol., vol. 136, no. 1/2, pp. 31-44, Jan. 2006.

[41] G. Sepulcre-Cantó, P. Zarco-Tejada, J. Jiménez-Muñoz, J. Sobrino, M. Soriano, E. Fereres, V. Vega, and M. Pastor, "Monitoring yield and fruit quality parameters in open-canopy tree crops under water stress. Implications for ASTER," Remote Sens. Environ., vol. 107, no. 3, pp. 455-470, Apr. 2007.

[42] A. Blum, J. Mayer, and G. Gozlan, "Infrared thermal sensor of plant canopies as a screening technique for dehydration avoidance in wheat," Field Crops Res., vol. 5, pp. 137-146, 1982.

[43] M. Reynolds, R. Singh, A. Ibrahim, O. Ageeb, A. Larqué-Saavedra, and J. S. Quick, "Evaluating physiological traits to complement empirical selection for wheat in warm environments," Euphytica, vol. 100, no. 1-3, pp. 85-94, Apr. 1998.

[44] S. Herwitz, J. Leung, R. Higgins, S. Dunagan, and J. Arvesen, "Remote command-and-control of imaging payloads using commercial off-theshelf technology," in Proc. IEEE IGARSS, 2002, vol. 5, pp. 2726-2728.

[45] S. Herwitz, L. Johnson, S. Dunagan, R. Higgins, D. Sullivan, J. Zheng, B. Lobitz, J. Leung, B. Gallmeyer, M. Aoyagi, R. Slye, and J. Brass, "Imaging from an unmanned aerial vehicle: Agricultural surveillance and decision support," Comput. Electron. Agric., vol. 44, no. 1, pp. 49-61, Jul. 2004.

[46] L. Johnson, S. Herwitz, S. Dunagan, B. Lobitz, D. Sullivan, and R. Slye, "Collection of ultra high spatial and spectral resolution image data over California vineyards with a small UAV," in Proc. Int. Symp. Remote Sens. Environ., Honolulu, HI, Nov. 10-14, 2003.

[47] J. Everaerts, "PEGASUS-Bridging the gap between airborne and spaceborne remote sensing," in New Strategies For European Remote Sensing, M. Oluic, Ed. Netherlands: Millpress Science Publishers, 2005, pp. 395-401.

[48] F. Esposito, G. Rufino, and A. Moccia, "1st mini-UAV integrated hyperspectral/thermal electro-optical payload for forest fire risk management," in Proc. AIAA Infotech Aerosp. Conf., 2007, vol. 1, pp. 653-665.

[49] F. Esposito, G. Rufino, A. Moccia, P. Donnarumma, M. Esposito, and V. Magliulo, "An integrated electro-optical payload system for forest fires monitoring from airborne platform," in Proc. IEEE Aerosp. Conf., 2007, pp. 1-13.

[50] R. Sugiura, N. Noguchi, and K. Ishii, "Remote-sensing technology for vegetation monitoring using an unmanned helicopter," Biosyst. Eng., vol. 90, no. 4, pp. 369-379, Apr. 2005.

[51] X. Haitao and T. Lei, "An autonomous helicopter system for aerial image collection," in Proc. ASABE Annu. Int. Meeting, Tech. Papers, Minneapolis, MN, Jun. 2007. Paper 071136.

[52] K. Lambers, H. Eisenbeiss, M. Sauerbier, D. Kupferschmidt, T. Gaisecker, S. Sotoodeh, and T. Hanusch, "Combining photogrammetry and laser scanning for the recording and modelling of the late intermediate period site of Pinchango Alto, Palpa, Peru," J. Archaeol. Sci., vol. 34, no. 10, pp. 1702-1712, Oct. 2007.

[53] J. Gamon, J. Penuelas, and C. Field, "A narrow-waveband spectral index that tracks diurnal changes in photosynthetic efficiency," Remote Sens. Environ., vol. 41, no. 1, pp. 35-44, Jul. 1992.

[54] R. Y. Tsai, "Versatile camera calibration technique for high-accuracy 3D machine vision metrology using off-the-shelf TV cameras and lenses," IEEE J. Robot. Autom., vol. RA-3, no. 4, pp. 323-344, Aug. 1987.

[55] J. Heikkilä and O. Silvén, "A four-step camera calibration procedure with implicit image correction," in Proc. IEEE Comput. Soc. Conf. CVPR, San Juan, PR, 1997, pp. 1106-1112.

[56] J. Bouguet, Camera Calibration Toolbox for Matlab, 2001. [Online]. Available: http://www.vision.caltech.edu/bouguetj/calib doc/index.html

[57] P. R. Wolf, Elements of Photogrammetry. New York: McGraw-Hill, 1983.

[58] G. M. Smith and E. J. Milton, "The use of the empirical line method to calibrate remotely sensed data to reflectance," Int. J. Remote Sens., vol. 20, no. 13, pp. 2653-2662, Sep. 1999.

[59] J. W. Rouse, R. H. Haas, J. A. Schell, D. W. Deering, and J. C. Harlan, "Monitoring the vernal advancements and retrogradation of natural vegetation," NASA/GSFC, Greenbelt, MD, p. 371, 1974. Final Report.

[60] D. Haboudane, J. R. Miller, N. Tremblay, P. J. Zarco-Tejada, and L. Dextraze, "Integrated narrow-band vegetation indices for prediction of crop chlorophyll content for application to precision agriculture," Remote Sens. Environ., vol. 81, no. 2/3, pp. 416-426, Aug. 2002.

[61] C. S. T. Daughtry, C. L. Walthall, M. S. Kim, E. B. de Colstoun, and J. E. McMurtrey, "Estimating corn leaf chlorophyll concentration from 
leaf and canopy reflectance," Remote Sens. Environ., vol. 74, no. 2, pp. 229-239, Nov. 2000.

[62] G. Rondeaux, M. Steven, and F. Baret, "Optimization of soil-adjusted vegetation indices," Remote Sens. Environ., vol. 55, no. 2, pp. 95-107, Feb. 1996.

[63] S. Dobrowski, J. Pushnik, P. Zarco-Tejada, and S. Ustin, "Simple reflectance indices track heat and water stress-induced changes in steadystate chlorophyll fluorescence at the canopy scale," Remote Sens. Environ., vol. 97, no. 3, pp. 403-414, Aug. 2005.

[64] L. Suárez, P. Zarco-Tejada, G. Sepulcre-Cantó, O. Pérez-Priego, J. R. Miller, J. C. Jiménez-Muñoz, and J. Sobrino, "Assessing canopy PRI for water stress detection with diurnal airborne imagery," Remote Sens. Environ., vol. 112, no. 2, pp. 560-575, Feb. 2008.

[65] F. J. Villalobos, F. Orgaz, and L. Mateos, "Nondestructive measurement of leaf-area in olive (Olea-Europaea L) trees using a gap inversion method," Agric. For. Meteorol., vol. 73, pp. 29-42, 1995.

[66] S. Jacquemoud and F. Baret, "Prospect: A model of leaf optical properties spectra," Remote Sens. Environ., vol. 34, no. 2, pp. 75-91, Nov. 1990.

[67] P. R. J. North, "Three-dimensional forest light interaction model using a Monte Carlo method," IEEE Trans. Geosci. Remote Sens., vol. 34, no. 4, pp. 946-956, Jul. 1996.

[68] J. Sobrino, Z. Li, G. Soria, and J. Jimenez, "Land surface temperature and emissivity retrieval from remote sensing data," Recent Res. Develop. Geophys., vol. 4, pp. 21-44, 2002.

[69] P. Dash, F. M. Göttsche, F. S. Olesen, and H. Fischer, "Land surface temperature and emissivity estimation from passive sensor data: Theory and practice-current trends," Int. J. Remote Sens., vol. 23, no. 13, pp. 2563-2594, Jul. 2002.

[70] Y. H. Kerr, J. P. Lagouarde, F. Nerry, and C. Ottlé, "Land surface temperature retrieval techniques and applications: Case of AVHRR," in Thermal Remote Sensing, D. A. Quattrochi and J. C. Luvall, Eds. Boca Raton, FL: CRC Press, 2004, pp. 30-109.

[71] A. Berk, G. Anderson, P. Acharya, J. Chetwynd, L. Bernstein, E. Shettle, M. Matthew, and S. Adler-Golden, MODTRAN4 User's Manual. Hanscom AFB, MA: Air Force Res. Lab., 1999.

[72] J. W. Salisbury and D. M. D'Aria, "Emissivity of terrestrial materials in the 8-14 $\mu \mathrm{m}$ atmospheric window," Remote Sens. Environ., vol. 42, no. 2, pp. 83-106, Nov. 1992.

[73] P. Agouris and T. Schenk, "Automated aerotriangulation using multiple image multipoint matching," Photogramm. Eng. Remote Sens., vol. 62, no. 6, pp. 703-710, 1996.

[74] D. Grejner-Brzezinska, C. Toth, and Y. Yi, "On improving navigation accuracy of GPS/INS systems," Photogramm. Eng. Remote Sens., vol. 71, no. 4, pp. 377-389, 2005 .

[75] E. Fereres and M. Soriano, "Deficit irrigation for reducing agricultural water use," J. Exp. Bot., vol. 58, no. 2, pp. 147-159, 2007.

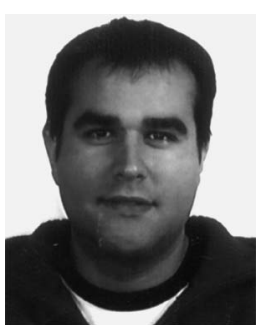

Jose A. J. Berni (S'07) received the degree in agricultural engineering from the Faculty of Agricultural Engineering and Forestry, University of Córdoba, Córdoba, Spain. He is currently working toward the $\mathrm{Ph} . \mathrm{D}$. degree in remote sensing and plant water management at the Institute for Sustainable Agriculture, Spanish Council for Scientific Research, Córdoba.

His research interests include remote sensing detection of water stress through high-resolution thermal imagery and the development of unmanned aerial platforms for remote sensing purposes.

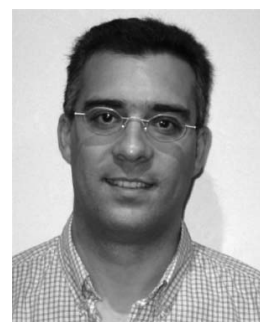

Pablo J. Zarco-Tejada received the degree in agricultural engineering from the Faculty of Agricultural Engineering and Forestry, University of Córdoba, Córdoba, Spain, the M.S. degree in remote sensing from the University of Dundee, Scotland, U.K., and the $\mathrm{Ph} . \mathrm{D}$. degree in earth and space science from York University, Toronto, ON, Canada.

He was a Contract Faculty for remote sensing with the University of California, Davis. He has worked on hyperspectral data to estimate leaf biochemical and canopy biophysical variables through leaf and canopy modeling, and the effects of chlorophyll fluorescence on leaf apparent reflectance through radiative transfer simulation. $\mathrm{He}$ is currently with the Institute for Sustainable Agriculture, Spanish Council for Scientific Research, Córdoba.

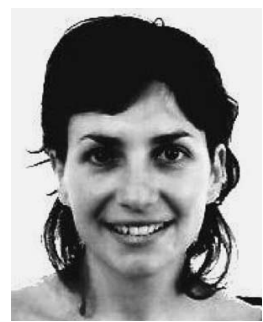

Lola Suárez received the degree in agricultural engineering from the University of Córdoba, Córdoba, Spain, and the M.Sc. degree in GIS and remote sensing from Wageningen University, HB Wageningen, The Netherlands. She is currently working toward the Ph.D. degree in hyper/multispectral remote sensing techniques to assess water stress and pigment related biophysical processes in vegetation at the Institute for Sustainable Agriculture, Spanish Council of Scientific Research, Córdoba.

Her research interests include crop biophysical properties, high-resolution hyper/multispectral remote sensing, and radiative transfer modeling for detecting water and nutrient stress on vegetation.

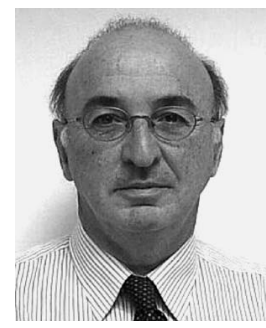

Elias Fereres received the Dr.Ing. Agr. degree from the Polytechnic University of Madrid, Madrid, Spain, in 1969, and the Ph.D. degree in ecology from the University of California, Davis, in 1976.

$\mathrm{He}$ is currently with the Institute for Sustainable Agriculture, Spanish Council for Scientific Research, Córdoba, Spain, and also with the Departamento de Agronomía, University of Córdoba, Córdoba. He has broad interests in agricultural water management and conservation. He has directed 27 doctoral theses and has published over 110 papers and book chapters, including chapters in the irrigation monographs of the American Society of Agronomy and the American Society of Agricultural Engineers.

Dr. Fereres is a Coeditor of Irrigation Science (Springer), a member of the Technical Advisory Committee of the CGIAR, and a former President of the European Society for Agronomy. 